\title{
12
}

\section{The Influence of Nanoporosity on the Behavior of Carbon-Bearing Fluids}

\author{
DAVID COLE AND ALBERTO STRIOLO
}

\subsection{Introduction}

Porosity and permeability are key variables linking the origin, form, movement, and quantity of carbon-bearing fluids that collectively dictate the physical and chemical evolution of fluid-gas-rock systems. ${ }^{1}$ The distribution of pores, pore volume, and their connectedness vary widely, depending on the Earth material, its geologic context, and its history. The general tendency is for porosity and permeability to decrease with increasing depth, along with pore size and/or fracture aperture width. Exceptions involve zones of deformation (e.g. fault or shear zones), regions bounding magma emplacement and subduction zones. Pores or fractures display three-dimensional hierarchical structures, exhibiting variable connectivity defining the pore and/or fracture network. ${ }^{2-5}$ This network structure and topology control: (1) internal pore volumes, mineral phases, and potentially reactive surfaces accessible to fluids, aqueous solutions, volatiles, inclusions, etc. ${ }^{6-8}$; and (2) diffusive path lengths, tortuosity, and the predominance of advective or diffusive transport. $^{9-12}$ For solids dominated by finer networks, transport is dominated by slow advection and/or diffusion. ${ }^{13-16}$

Despite the extensive spatial and temporal scales over which fluid-mineral interactions can occur in geologic systems, interfacial phenomena including fluids at mineral surfaces or contained within buried interfaces such as pores, pore throats, grain boundaries, microfractures, and dislocations (Figure 12.1) impact the nature of multiphase flow and reactive transport in geologic systems. ${ }^{13,17-21}$ Complexity in fluid-mineral systems takes many forms, including the interaction of dissolved constituents in water, wetting films on mineral surfaces, adsorption of dissolved and volatile species, the initiation of reactions, and transport of mobile species. ${ }^{22-24}$ Direct observations and modeling of physical (transport) and chemical properties (reactivity) and associated interactions are challenging when considering the smallest length scales typical of pore and fracture features and their extended three-dimensional network structures. ${ }^{25,26}$

The various void types and their evolution during reaction with fluids are critically important factors controlling the distribution of the fluid-accessible pore volume, flow dynamics, fluid retention, chemical reactivity, and contaminant species transport. ${ }^{27-32}$ While fracture-dominated flow can be volumetrically dominant in shallow crustal settings 


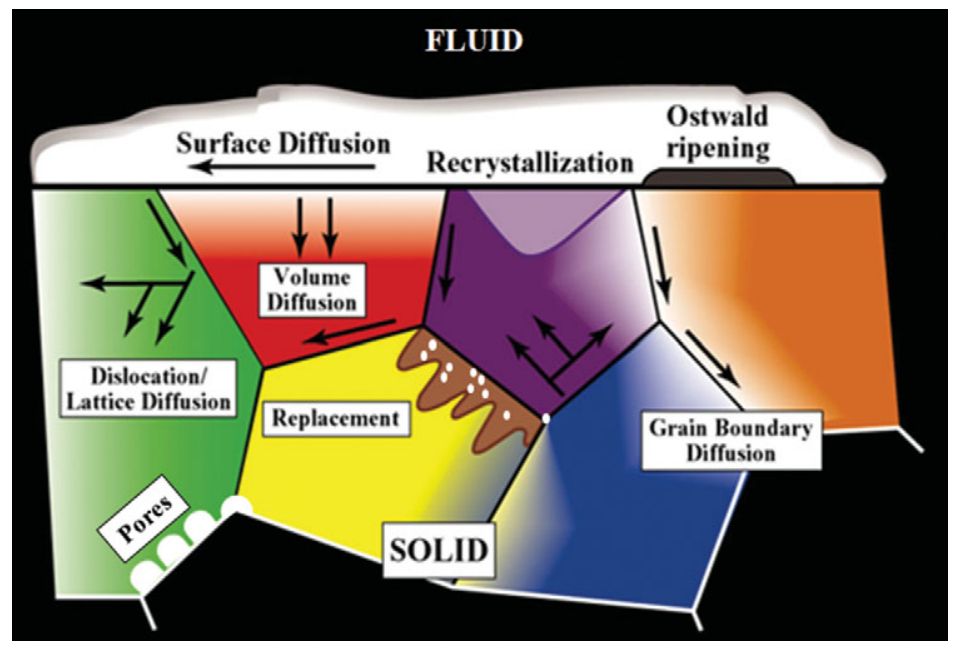

Figure 12.1 Schematic illustration of the various mass transfer and diffusion processes that can control the behavior of fluids and dissolved species in a heterogeneous crystalline matrix.

or in zones of deformation, ${ }^{33-38}$ there is a continuum of coupled reaction-transport phenomena at length scales from fractures to the smallest nanopores. Nanoscale pores may interconnect larger volumes, act as pore throats, and play an important role in fracture initiation. Diffusion of chemical constituents from pore fluids along grain boundaries and into solids may drive the textural and chemical evolution of geologic media. ${ }^{38-41}$

There is general agreement that the collective structure and properties of bulk fluids are altered by solid substrates, confinement between two mineral surfaces, or in narrow pores due to the interplay of the intrinsic length scales of the fluid molecules and the length scale of fluid-solid (i.e. confinement) interactions. ${ }^{22,42-45}$ The combined effect of confinement and intermolecular forces, which vary among different mineral systems, results in unique (and poorly constrained) perturbations to a wide range of thermodynamic and transport parameters, generally different from those observed in the bulk phase. ${ }^{4-51}$ Also impactful is the degree of randomness of the matrix, geometry, surface composition (e.g. silicates, carbonates, organic matter $(\mathrm{OM})$ ), fractal nature of the pores, and connectivity of the pore network. $^{52}$

It has also been hypothesized that chemical reactions in pores smaller than $100 \mathrm{~nm}$ may be different from those in larger pores because of: (1) confinement-induced changes in fluid properties and associated solutes (e.g. electrolytes, $\left.\mathrm{scCO}_{2}, \mathrm{CH}_{4}\right)^{53}$; (2) shifts in thermodynamic equilibrium composition ${ }^{54-56}$; and (3) overlapping electric double layers and surface curvature, distribution of preferential adsorption sites, surface charge, and counterion behavior. ${ }^{57}$ The question as to whether surface chemical processes (e.g. ionization, complexation, adsorption) in nanopores differ from those in macropores $(>100 \mathrm{~nm})$ remains largely unresolved. Compounding this is the formidable challenge in 
characterizing the structure and dynamics of fluid species within internal pore or fracture networks. ${ }^{13}$ Predictions on the direction and magnitude of changes in chemical reactions have not been thoroughly explored, despite the fact that the large surface area contributed by smaller pores can make them extremely significant in fluid-rock interactions. ${ }^{6-8,58}$

This chapter seeks to show how the structure of nanoconfined fluids is responsible for a variety of effects relevant to the origin, form, movement, and quantity of carbon-bearing fluids. "Form" is related to the molecular structure of confined fluids, which includes segregation of molecular species across the pore. In Section 12.3, we discuss how form is related to "movement," which is reflected by the diffusion and transport mechanisms of confined fluids. In Section 12.4, we discuss how form relates to "quantity" (i.e. the solubility of gases in confined fluids). In Section 12.5, we discuss how form is related to "origin," restricted to the reactivity of nanoconfined fluids.

The richness and complexity of fluid behavior (e.g. phase transitions, molecular orientation and relaxation, diffusion, adsorption, wetting, capillary condensation, etc.) in confined geometries underscores the need to adopt a multidisciplinary approach. In concert with molecular simulations, there is a robust set of experimental approaches used to directly or indirectly probe the behavior of fluids at interfaces or in nanopore confinement. The reader is referred to our previous research ${ }^{22}$ and to a number of excellent reviews on molecular dynamics (MD) ${ }^{50,55,59-64}$ and experimental methods and outcomes. ${ }^{65-71}$

\subsection{Nanopore Earth Materials and Fluids}

\subsubsection{Nanopore Features}

Porosity and permeability are key variables that link the thermal, hydrologic, geomechanical, and geochemical behavior exhibited by most, if not all, fluid-rock systems. In general, there is a strong positive correlation between porosity and permeability in many porous and fractured geologic media (see Nelson ${ }^{72}$ for sedimentary rocks and Ingebritsen et al. $^{73}$ for crystalline rocks). What is truly remarkable is the extraordinary range in measured permeability (some 16 orders of magnitude), from as high as $10^{-7} \mathrm{~m}^{2}$ $\left(10^{5}\right.$ Darcy) for well-sorted gravel to as low as $10^{-23} \mathrm{~m}^{2}$ (sub-nano Darcy) in crystalline rocks, mudstones (shale), fault gouges, and halide deposits. ${ }^{38,74}$ An assortment of measurements (e.g. deep borehole, core-scale flooding, geophysical) indicates that both porosity and permeability tend to decrease with increasing depth. For example, permeability measurements of core obtained from the Kola superdeep well (11.4-12.0 km) range from $10^{-17}$ to $10^{-22} \mathrm{~m}^{2}$, depending on the effective confining pressure. ${ }^{75} \mathrm{In}$ a series of seminal papers, Ingebritsen and Manning ${ }^{76-78}$ described the permeability of continental crust as a function of depth in the context of specific geologic settings. They demonstrated that permeabilities decreased rapidly through the brittle portion of the crust to values between $10^{-14}$ and $10^{-16} \mathrm{~m}^{2}$ at a depth of approximately $10 \mathrm{~km}$. Below this depth through the brittle-ductile transition zone $(\sim 10-15 \mathrm{~km})$ extending to depths of roughly $25 \mathrm{~km}$, the permeability becomes more constant with depth, ranging between $10^{-16}$ and $10^{-18} \mathrm{~m}^{2}$. 

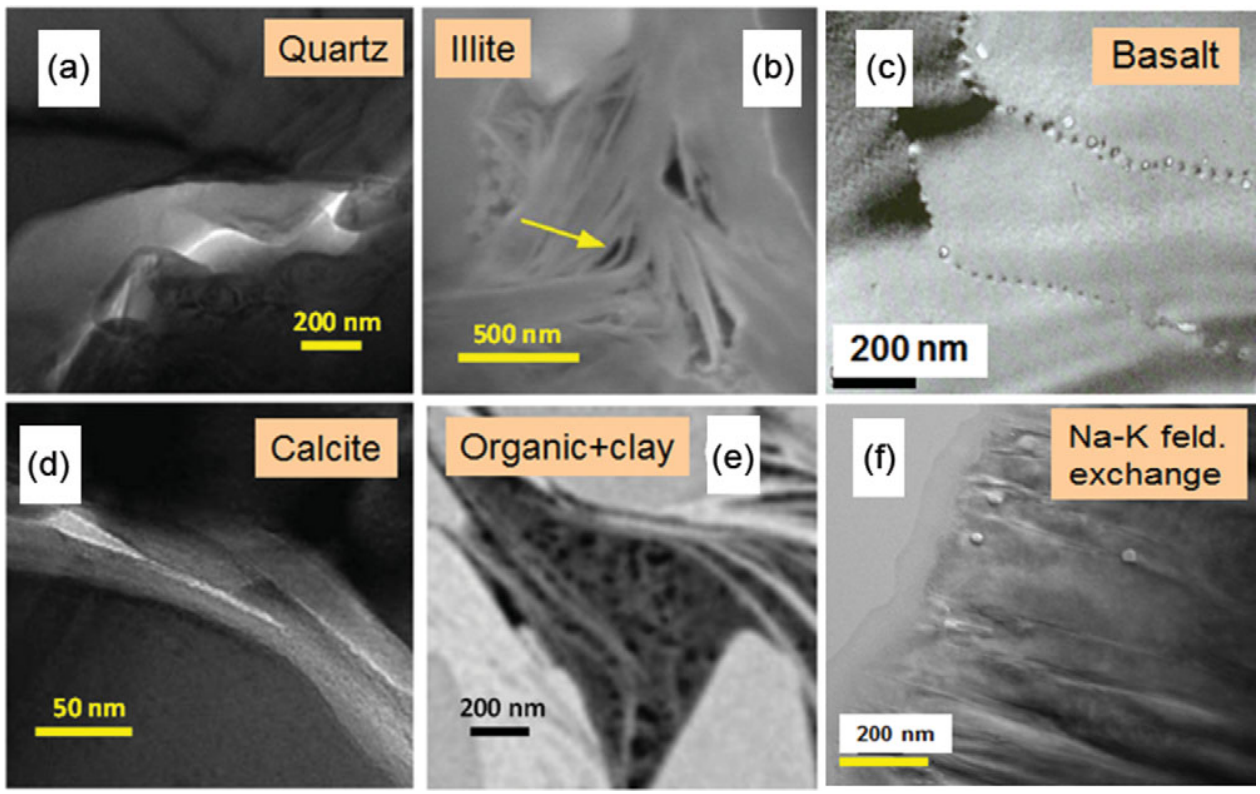

Figure 12.2 Transmission electron microscopy images of different nanoscale pores. (a) St. Peter sandstone, Wisconsin; (b) illite from Utica shale, Ohio; (c) basalt clast, Costa Rica; (d) Hueco limestone, north Mexico; (e) organic embedded in clay, Utica shale, Ohio; (f) experimental hydrothermal replacement of adularia by albite, $600^{\circ} \mathrm{C}, 200 \mathrm{MPa}$.

Norton and Knapp ${ }^{39}$ documented the porosity of numerous crystalline rocks and classified pores (fractures) into three broad categories: flow, diffuse, and residual (isolated). Of these, the first two are relevant to the nature of the permeability regimes, in that the smaller, sometimes dead-ended diffuse pores and pore throats contribute to the chemistry of the larger, throughgoing connected pores and fractures (i.e. flow porosity). The diffuse porosity estimates identified by Norton and Knapp ${ }^{39}$ for volcanic and crystalline rocks range from $0.01 \%$ to $10 \%$. Bredehoeft and Norton ${ }^{79}$ expanded on this by providing estimates of permeability for fractured igneous and metamorphic rocks that range from $10^{-12}$ to $10^{-16} \mathrm{~m}^{2}$, and for unfractured equivalents ranging from $10^{-17}$ to $10^{-20} \mathrm{~m}^{2}$. Anovitz and Cole ${ }^{80,81}$ surveyed the many techniques used to quantify pore features (e.g. advanced electron microscopy, X-ray, and neutron scattering) and indicated that the range in pore size measured in rocks (sedimentary, igneous, and metamorphic) can vary by approximately eight orders of magnitude from the nanometer scale to the millimeter scale.

General nanoscale features observed in many rocks include intergranular or interparticle (Figure 12.2a, c, and d) versus intraparticle porosity (Figure 12.2b, e, and f). The latter pore type is frequently the result of dissolution-precipitation processes and is typically less well connected to the flow porosity compared to intergranular porosity involving grain-to-grain contacts of two different phases known as interphase boundaries or grain boundaries, defined as the interface of two grains of the same phase. The intergranular pore type is 

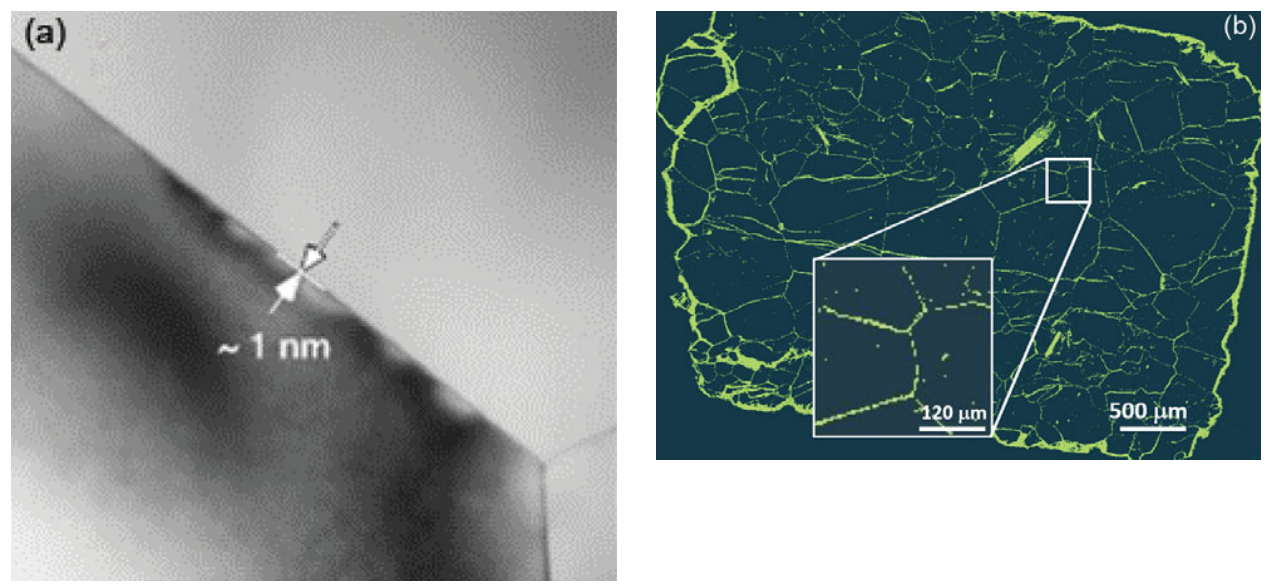

Figure 12.3 (a) High-resolution transmission electron microscopy image of the San Carlos olivine grain boundary and triple junction (from Marquardt and $\mathrm{Faul}^{41}$ ). Note the estimated grain boundary width of $\sim 1 \mathrm{~nm}$. (b) Balsam Gap dunite showing the extent of fluid infiltration and serpentinization along olivine grain boundaries, hydrothermally treated at $300^{\circ} \mathrm{C}, 200 \mathrm{MPa}$.

Reprinted with permission from Marquardt K, Faul UH. The structure and composition of olivine grain boundaries: 40 years of studies, status and current developments. Phys Chem Miner 2018; 45: 139-172. ${ }^{41}$ Copyright 2018 Physics and Chemistry of Minerals.

thought to control transport in very tight rocks, especially those encountered deeper in the crust and mantle. As Wark and Watson ${ }^{82}$ point out, the premise is that rocks below the brittle-ductile transition ( $>12 \mathrm{~km}$ for continental crust) cannot sustain a fracture network system, and thus fluids - especially at low-volume fractions - must reside in intergranular pores. Intergranular fluids, however, will flow only if the pores (i.e. grain boundaries in this case) are interconnected. Fluid flow may be a misnomer when discussing very deep-seated rocks. The width of space between grains in very deep crustal and mantle rocks (e.g. olivine-rich mantle) has been a source of debate for many years. Marquardt and Faul ${ }^{41}$ provided an excellent summary of the structure and composition of olivine grain boundaries and conclude that the width is on the order of $1 \mathrm{~nm}$ or less (Figure 12.3a). At this reduced dimension, fluid mobility takes the form of grain boundary diffusion, which can be several orders of magnitude greater than volume (lattice) diffusion through minerals, but many orders of magnitude slower than advective flow. ${ }^{83-85}$ Nevertheless, fluids do penetrate these spatially restricted domains, as evidenced by dissolution, grain boundary migration, and phase alteration (e.g. olivine conversion to serpentine) (Figure 12.3b). High-resolution transmission electron microscopy reveals that some olivine-rich rocks like the San Carlos olivine also display amorphous films that are 1-2 $\mathrm{nm}$ wide between olivine grains thought to be remnant melt. ${ }^{86}$

The presence of nanoscale pores and fractures seems to be widespread in Earth materials and may be extremely significant for controlling fluid accessibility in deep-seated crustal and upper-mantle rocks depending on the extent of pore network connectivity. 
Pores may be either slit-like or cylindrical in shape and can exist along grain boundaries, at the contact of unlike grains (interphase boundaries), or entirely within a given phase. In simplest terms, the pore surface compositions are dominated by silica or silicates, oxides, clay, carbonate, and, where present, OM of varying thermal maturity. As we discuss below, it is at the dimensions of a few nanometers to tens of nanometers that fluid properties deviate significantly from those of the bulk fluids.

\subsubsection{Fluid Properties Affected by Nanoconfinement}

It has been reported that the collective structure and properties of bulk fluids are altered by confinement between two surfaces or in narrow pores due to the interplay of the intrinsic length scales of the fluid and the length scale due to confinement. ${ }^{87-89}$ For example, melting/freezing of water is affected by confinement in geomaterials, ${ }^{90,91}$ and confined fluids can be liquid at the thermodynamic conditions (pressure and temperature) at which the correspondent bulk fluids are gaseous. It has also been shown that confinement can promote new phases that simply do not exist in the bulk. ${ }^{92}$ This has been an area of particular interest to those who investigate the properties of water. It has been demonstrated that confined water can be prevented from freezing at conditions well inside the "no-man's land." 93 It is possible that similar effects will also be observed for carbon-bearing fluids, although perhaps the high temperature in the subsurface will prevent the formation of exotic phases. In point of fact, almost any fluid property is influenced by nanoconfinement to a varying degree: thermophysical (e.g. density, phase behavior, dielectric constant, compressibility), transport (e.g. diffusion, shear), dynamical motion (translational, rotational, vibrational, and librational), and interfacial interactions (e.g. adsorption, wetting, solubility) are expected to be strongly dependent upon confinement.

\subsection{Form and Movement: Transport Mechanisms under Nanoconfinement}

The main mechanisms responsible for fluid transport are convective motion and molecular diffusion. When the pore size becomes of the order of magnitude of fluid molecules (i.e. in nanopores), diffusion can become the dominant mechanism. Because in the subsurface many pores are in this size regime, it is important to understand the mechanisms by which molecular diffusion can take place in nanopores. In this section, we discuss how the structure of confined fluids (form) affects their transport (movement). We focus on fluid mixtures. The studies summarized here are selected primarily from the body of work produced by the authors. Future investigations will stress the wide applicability of our extrapolations.

As a first example, we refer to Chiavazzo et al., ${ }^{94}$ who used computer simulation to investigate water transport in "nanoconfined geometries" (i.e. within nanopores, around nanoparticles, carbon nanotubes, and proteins). Almost 60 cases were considered, some being obtained from the literature. The results, reproduced in Figure 12.4, were interpreted using a general phenomenological relationship: 

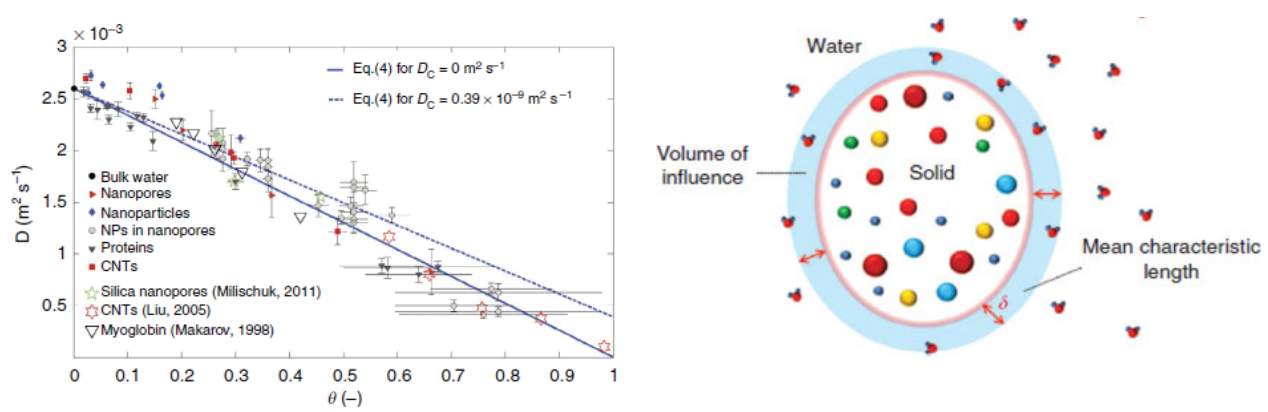

Figure 12.4 (Left) Self-diffusion coefficient for nanoconfined water as a function of the ratio $\theta$ between "surface" and total water volumes. The image contains simulation results for many systems. (Right) Schematic illustrating the region of influence of a solid substrate on an interfacial fluid.

Figure reproduced from Chiavazzo E, Fasano M, Asinari P, Decuzzi P. Scaling behaviour for the water transport in nanoconfined geometries. Nat Commun 2014; 5: 3565. ${ }^{94}$ Permission granted from Creative Commons https:// creativecommons.org/licenses/by/3.0.

$$
D(\theta)=D_{B}\left[1+\left({ }^{D_{C}} / D_{B}-1\right) \theta\right] .
$$

In (12.1), $D$ is the overall self-diffusion coefficient of water calculated in the various systems and $D_{C}$ and $D_{B}$ are the self-diffusion coefficients estimated for confined and bulk water, respectively. According to this relationship, $D$ was found to scale linearly with the ratio $\theta$ between "surface" and total water volumes. The "surface" water volume is a measure of the interfacial region where water molecules are in contact with the confining material. As the pore width decreases, the amount of "surface" versus total volume increases.

\subsubsection{Steric Effects Enhance Surface versus Pore Diffusion}

When fluid molecules are confined within nanopores, they can experience a strong attraction to the pore surfaces (e.g. via hydrogen bonds). It is possible that the molecules strongly adsorbed on a surface show very slow diffusion parallel to the surface (i.e. surface diffusion). This is because to move from one adsorption site to an adjacent one, the fluid molecules need to be released from one strong interaction. Hopping mechanisms can be observed, in which one molecule hops from one preferential adsorption site to the next. As the adsorption energy becomes stronger, the frequency of such hops lowers, and diffusion is delayed. If the preferential adsorption sites are so close to each other that hopping is not necessary, it is possible to observe sliding. ${ }^{95}$ It is generally assumed that surface diffusion is slower than that near the pore center (i.e. "pore diffusion"). For a pure fluid, as the pore size decreases, the contribution of surface diffusion increases compared to that of surface diffusion, as shown in Figure 12.4 in the case of water.

However, we also know that the opposite situation can also arise. Phan et al. ${ }^{44}$ considered a fluid mixture composed of ethanol and water inside a slit-shaped alumina 
nanopore of width $1 \mathrm{~nm}$. The pore surface exposed a high density of -OH groups. Equilibrium studies on a flat surface ${ }^{43}$ showed that water preferentially adsorbs on the alumina substrate and displaces ethanol molecules, should these be present on the surface. When the pore is of $1 \mathrm{~nm}$, the physical state of the system, depending on composition, can present one layer of water on each of the two pore surfaces, with ethanol near the pore center. The pore width is so narrow that steric effects hinder the diffusion of ethanol near the pore center, while water surface diffusion is possible. This effect disappears when the pore width increases. A detailed analysis of the trajectories of the confined water molecules showed that the diffusion of water is characterized by hops. Such hops are from one adsorption site to another one on the surface across the pore volume. This mechanism becomes hindered as the pore width increases because the water molecules would have to transport across a large region filled with ethanol. In this example, increasing pore width delays water surface diffusion while allowing faster ethanol pore diffusion.

Complementary experimental investigations are difficult because it is hard to differentiate between molecules that are adsorbed on the surface from those that accumulate near the pore center. Some experimental results, however, suggest that, in some cases, surface diffusion can be the dominant transport mechanism. For example, Kim et al. ${ }^{96}$ synthesized "silylated" mesoporous silica membranes. The chemical functionalization made the pore surfaces more attractive for ethanol than for water. Once exposed to water-ethanol liquid mixtures, ethanol permeated the membranes much faster than water, suggesting that surface diffusion became an important mechanism of transport. Ge et al. ${ }^{97}$ used zeolites to enhance polymer-based composite membranes. The zeolites preferentially attracted water, and separation factors of $\sim 10,000$ were achieved in water-removal pervaporation processes (i.e. water permeated these membranes much faster than ethanol). For completeness, it should be remembered that the permeability of a membrane is equal to the product of the diffusion coefficient of the fluid through the membrane and the amount adsorbed. Thus, enhanced diffusion might not be the only mechanism responsible for the results just discussed.

\subsubsection{Molecular Lubrication Enhances Pore Diffusion}

Even in the absence of preferential adsorption sites where nonspecific attractive interactions lead to an accumulation of fluids near pore surfaces, it is generally expected that the diffusion of the fluid molecules in a nano- to meso-pore is slower than that in the bulk. For example, the enhanced fluid density near the pore walls leads to more frequent fluid-fluid and fluid-pore collisions, which reduce the mean free path and the diffusion coefficient. This expectation is demonstrated, for example, by quasielastic neutron scattering (QENS) experiments conducted for ethane in the gas phase. When ethane was confined in two $\mathrm{SiO}_{2}$ pore-glass materials with pore sizes 11.1 and $41.5 \mathrm{~nm}$, the self-diffusion coefficient was found to be a factor of $\sim 4$ slower compared to that measured for bulk ethane at similar temperature-pressure conditions. ${ }^{98}$

If these results are due to the fluid accumulation near the pore interface, then it might be possible to enhance the fluid diffusion by adding small amounts of another fluid that 
preferentially adsorbs on the solid substrate. For example, Le et al. ${ }^{99,100}$ simulated systems containing a hydrocarbon (either butane or octane) and $\mathrm{CO}_{2}$ in a silica slit-shaped pore of width $\sim 2 \mathrm{~nm} . \mathrm{CO}_{2}$ formed molecularly thin layers on the pore surfaces, while the hydrocarbon filled the pore. At low dosages, $\mathrm{CO}_{2}$ enhanced hydrocarbon diffusion. These computational results were confirmed by Gautam et al. ${ }^{101}$ and Patankar et al., ${ }^{98}$ who used QENS to study the diffusion of propane and ethane in mesoporous $\mathrm{SiO}_{2}$, respectively, in the presence of $\mathrm{CO}_{2}$. The ethane experiments, conducted at different temperatures, showed that the activation energy of diffusion decreased in the presence of $\mathrm{CO}_{2}$ by a factor of $\sim 2$ compared to data obtained for pure ethane, which was consistent with the simulations. Others also reported that $\mathrm{CO}_{2}$ enhanced the diffusion of hydrocarbons through different porous materials. ${ }^{99,101,102}$

\subsubsection{Molecular Hurdles Due to Strong Fluid-Fluid Interactions}

The enhanced diffusion discussed in Section 12.3.2 is due to the preferential adsorption of $\mathrm{CO}_{2}$ to the pore surface, but one can ask whether similar observations are possible when a fluid other than $\mathrm{CO}_{2}$, also strongly attracted to the pore surface, is used. One such fluid could be water. Gautam et al. ${ }^{103}$ used QENS to probe whether this was the case. The system used contained propane and $\mathrm{D}_{2} \mathrm{O}$ in silica-based, cylindrical pores of diameter $\sim 1.5 \mathrm{~nm}$. The experimental results showed that the propane diffusion was depressed, rather than enhanced, by $\mathrm{D}_{2} \mathrm{O}$. Le et al. ${ }^{104}$ conducted MD simulations for a system mimicking the experimental one. The results showed that although water molecules are strongly adsorbed on the pore surface, the pores have such a narrow diameter and the water-water interactions are so strong that water molecules form molecular bridges across the pore volume. These bridges hinder propane diffusion. Simulation snapshots illustrating the phenomenon are shown in Figure 12.5.

The formation of water bridges was also found to delay methane transport across slitshaped muscovite pores. Ho and Striolo ${ }^{105}$ found that methane convective transport within slit-shaped pores carved out of muscovite and partially filled with water is strongly dependent on the relative orientation of the water bridges and that of imposed motion. When the water bridges are perpendicular to the direction of motion, methane transport is regulated by the movement of water, which adheres to the pore surface. When the water bridges are parallel to the direction of motion, fast methane transport is observed.

Phenomena such as those just described are expected to be important when lowsolubility or immiscible fluids are simultaneously present within a pore, and they are relevant for the production of shale gas, in which water is often used as the fracturing fluid. Many studies have addressed how methane could escape kerogen. These studies could be relevant for systems in which pores are extremely heterogeneous in geometry and of comparable size to the fluid molecules.

\subsubsection{Transport of Guest Molecules in Confined Fluids}

It is worth discussing the relation between the structure of fluids in confined water and their transport. Phan et al. ${ }^{106}$ simulated the transport of a mixture mimicking natural gas 

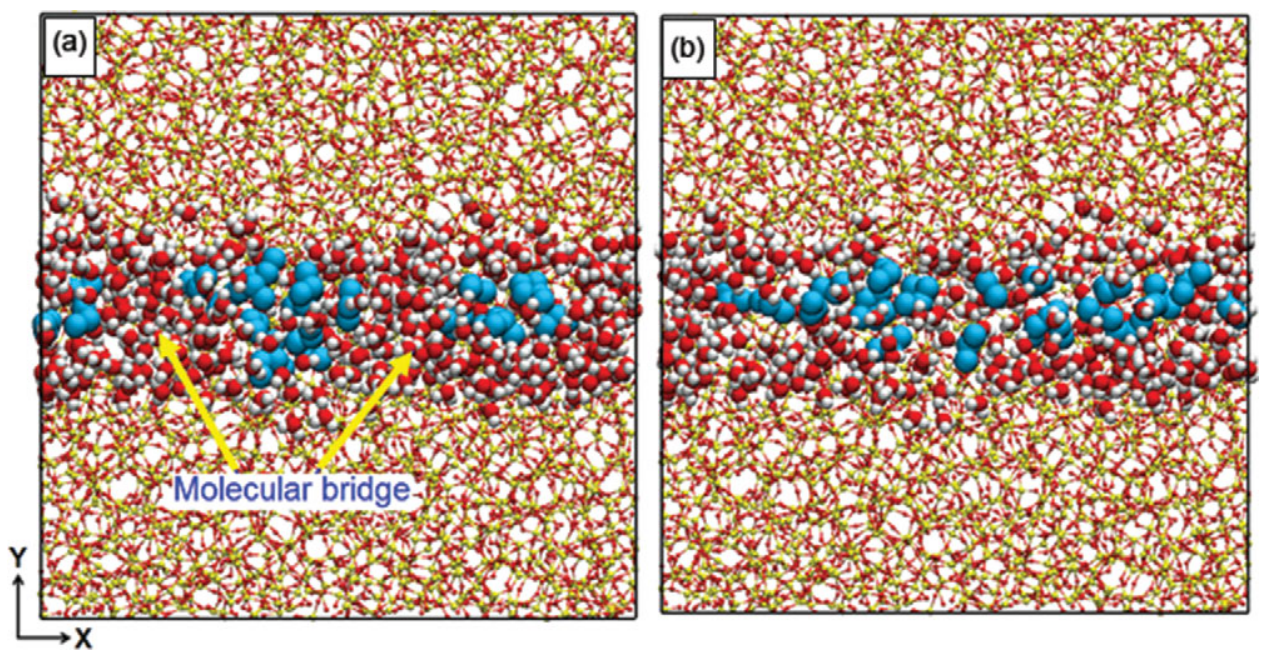

Figure 12.5 Simulation snapshots representing the effect of water molecular bridges (red and white spheres) on the transport of propane (cyan spheres) diffusing through a cylindrical pore carved out of amorphous silica (red and yellow spheres connected by lines). In (a), the water bridges hinder the transport at higher water/gas ratios $(\geq 17)$, while in (b), the bridges are dissociated and propane diffusion is faster at lower water/gas ratios $(\leq 12)$.

Reprinted with permission from Le TTB, Striolo A, Gautam S, Cole DR. Propane-water mixtures confined within cylindrical silica nanopores: structural and dynamical properties probed by molecular dynamics. Langmuir 2017; 33: $11310-11320 .{ }^{104}$ Copyright 2017 American Chemical Society.

(ethane, methane, and $\mathrm{H}_{2} \mathrm{~S}$ ) through nanopores filled with water. The results show that $\mathrm{H}_{2} \mathrm{~S}$ permeates the pores much faster than the other compounds and that ethane is too large to permeate the hydrated pores. Bui et al. ${ }^{107}$ extended the study to consider different porous materials. In the left-hand panel of Figure 12.6, we report the self-diffusion coefficient estimated for water in various nanopores: confinement reduces the self-diffusion of water, consistent with Figure 12.4. For reference, MD simulations yield a self-diffusion coefficient for bulk liquid water of $\sim 28 \times 10^{-10} \mathrm{~m}^{2} / \mathrm{s} .{ }^{108}$ The results in Figure 12.6 also show that the chemical properties of the minerals are important: all the pores considered have the same width and the simulation temperature is constant, yet the water self-diffusion coefficient varies by a factor of $\sim 2$. In the right-hand panel of Figure 12.6, we report the selfdiffusion coefficients estimated for aqueous methane confined in the water-bearing pores considered in the left-hand panel of Figure 12.6. There is a correlation between the selfdiffusion coefficient of water and that of aqueous methane, but there are also deviations. Bui et al. ${ }^{107}$ highlighted the fact that the diffusion of aqueous methane in calcite nanopores can be anisotropic (the diffusion along the $\mathrm{x}$-axis of the pore is about three times faster than that along the y-axis). For completeness, it is worth pointing out that anisotropic diffusion of hydrocarbons had been previously reported in nanopores carved out of calcite by Franco et al., ${ }^{109}$ suggesting that the surface structure of this solid material indeed affects the transport of the guest molecules. 

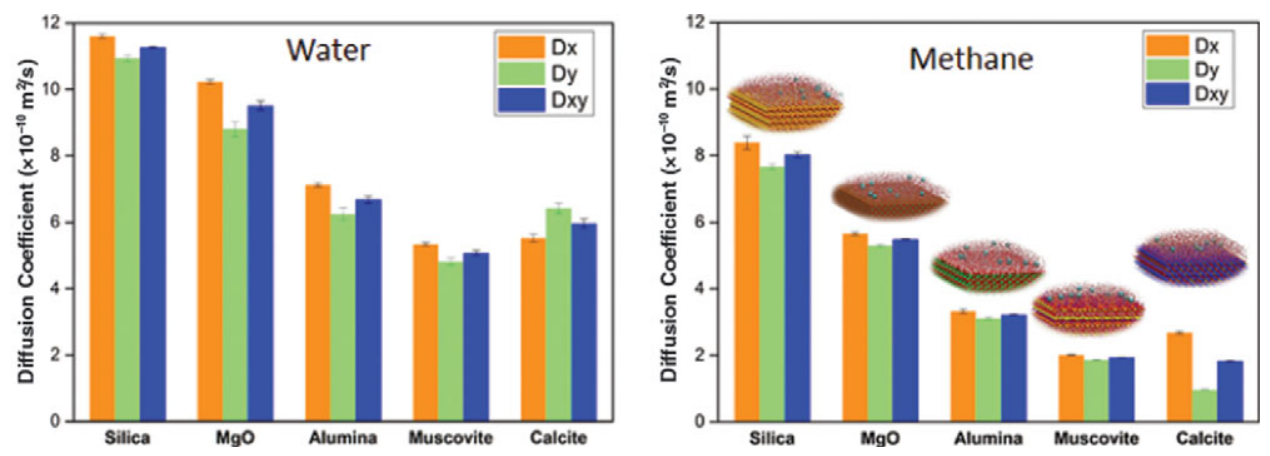

Figure 12.6 (Left) Self-diffusion coefficient for water in slit-shaped pores of width $1 \mathrm{~nm}$ carved out of different minerals at the same temperature. (Right) Self-diffusion coefficient for methane molecules dissolved in confined water. The results distinguish the diffusion coefficients along two perpendicular directions. While the self-diffusion coefficient for water is for the most part isotropic, that of aqueous methane in calcite pores is highly anisotropic, with transport along the $\mathrm{x}$-axis being much faster than that along the y-axis.

Reprinted with permission from Bui T, Phan A, Cole DR, Striolo A. Transport mechanism of guest methane in water-filled nanopores. J Phys Chem C 2017; 121: $15675-15686 .{ }^{107}$ Copyright 2017 American Chemical Society.

\subsubsection{Transport of Aqueous Electrolytes in Narrow Pores}

Argyris et al. ${ }^{110}$ and Ho et al. ${ }^{111}$ attempted to quantify the mobility of aqueous electrolytes at low concentration within narrow slit-shaped pores. The goal was to quantify potential differences in the mobility of $\mathrm{Cs}^{+}$and $\mathrm{Na}^{+}$ions, which have the same valence but significantly different size. The aqueous solutions were electrostatically balanced by $\mathrm{Cl}^{-}$ions. These MD simulations were conducted at similar conditions (1 M ionic strength, ambient temperature). The cristobalite silica pores were slit-shaped, with widths of $\sim 1.2 \mathrm{~nm}$. The surface chemistry was manipulated to replicate different $\mathrm{pH}$ scenarios. The results were quantified in terms of the self-diffusion coefficients of the electrolytes in the direction parallel to the pore surface. A strong correlation was observed between the preferential position of an ion in the direction perpendicular to the pore surface and its mobility. This correlation was interpreted based on prior results ${ }^{112,113}$ that revealed that the mobility of interfacial water strongly depends on the distance from the solid substrate, as well as on the protonation state of the surface. The results concerning ion mobility are summarized in Figure 12.7.

It is worth stressing that the results depend strongly on the properties of the pore surface. In fact, MD simulations by Rotenberg et al. ${ }^{114}$ have shown how $\mathrm{Cs}^{+}$ions tend to accumulate near clay surfaces, presumably because of the difference in surface charge. Because of the importance of preferential adsorption sites (e.g. see the recent contribution by Loganathan and Kalinichev ${ }^{115}$ ), which include pore edges, and because of the practical importance of quantifying ion migrations in the subsurface, advanced force fields are being developed to enhance the reliability of atomistic simulations, ${ }^{116-118}$ and various approaches are being developed to include hydrodynamics and multiscale properties in the calculations. ${ }^{119-122}$ 

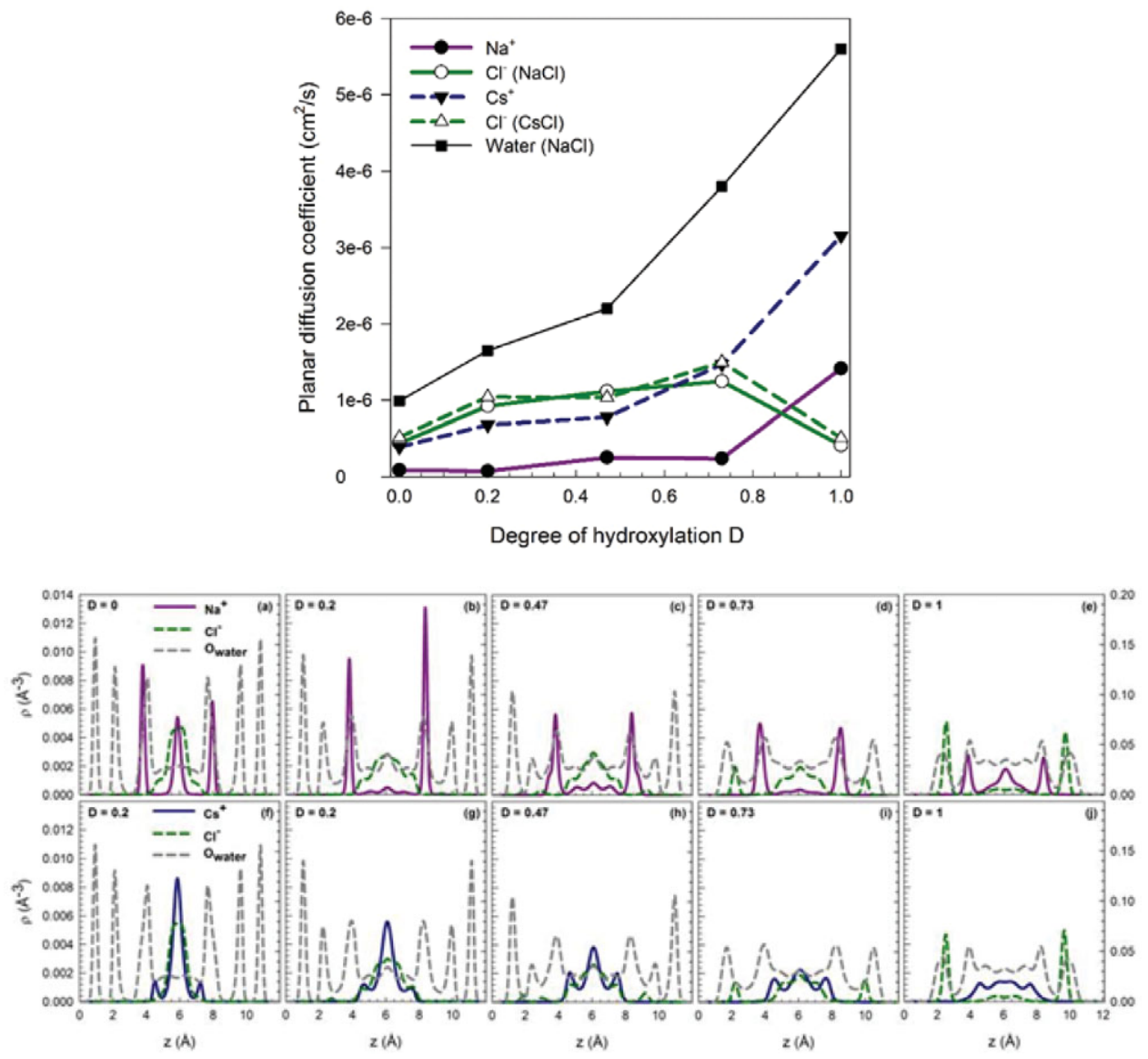

Figure 12.7 (Top) Self-diffusion coefficient estimated for different aqueous electrolytes and water in slit-shaped pores as a function of the degree of protonation $D(D=0$ in panel (a); $D=0.2$ in (b); $D=0.47$ in (c); $\mathrm{D}=0.73$ in (d); and $\left(\mathrm{D}=1\right.$ in (e)). In all systems, $\mathrm{Cs}^{+}$ions are more mobile than $\mathrm{Na}^{+}$ions. (Bottom) Density profiles in the direction perpendicular to the solid substrate, with the same degree of protonation as in Top panels (panels $\mathrm{f}-\mathrm{j}$ ). The density profiles discriminate $\mathrm{NaCl}$ and $\mathrm{CsCl}$ systems. In general, the $\mathrm{Cs}^{+}$ions accumulate near the centers of the pores, while $\mathrm{Na}^{+}$ions are more closely associated with the pore surfaces. Because the molecular mobility depends on the distance from the surface, slower near the surface, the preferential distribution correlates with the ionic mobility.

Reprinted with permission from Ho TA, Argyris D, Cole DR, Striolo A. Aqueous $\mathrm{NaCl}$ and $\mathrm{CsCl}$ solutions confined in crystalline slit-shaped silica nanopores of varying degree of protonation. Langmuir 2012; 28 : 1256-1266. ${ }^{111}$ Copyright 2012 American Chemical Society.

\subsection{Form and Quantity: Confinement Effects on Solubility}

To estimate the amounts of fluids present in the subsurface, one approach could be first to estimate the volume available (i.e. the accessible pore space) and then to use our understanding of bulk fluids to estimate the amount of fluids in such a volume at the subsurface pressure-temperature conditions. This approach is reasonable as long as the fluid behavior 
in the bulk is consistent with that in the subsurface, which it is for larger pores $(>100 \mathrm{~nm})$. In this section, we discuss the effects nanopores have on the structure of fluids ("form") that deviate markedly from the bulk. One property affected strongly by nanoconfinement is solubility. Another property of importance concerns the behavior of aqueous electrolytes in confinement. Because confinement alters the dynamics of water molecules, could it be that the dielectric constant of water in the deep subsurface differs strongly from that known in the bulk? Should this be the case, what are the implications regarding our still limited understanding of aqueous electrolytes in the subsurface?

\subsubsection{Volatile Gas Solubility in Confined Liquids}

Several studies reported an enhanced solubility of gases in liquids confined in small pores, ${ }^{123,124}$ a phenomenon referred to as "oversolubility." Luzar and Bratko ${ }^{125}$ reported 5-10-fold enhancements of $\mathrm{N}_{2}$ and $\mathrm{O}_{2}$ solubility in water in 38-43- $\AA$ hydrophobic pores. Experiments support these estimates. Pera-Titus et al. ${ }^{126}$ studied the solubility of $\mathrm{H}_{2}$ in $\mathrm{CHCl}_{3}, \mathrm{CCl}_{4}$, n-hexane, ethanol, and water within $\gamma$-alumina, silica, and MCM-41 and found that $\mathrm{H}_{2}$ solubility was enhanced by up to 15 times when the pore size was $<15 \mathrm{~nm}$. Rakotovao et al. ${ }^{127}$ confirmed these results using ${ }^{1} \mathrm{H}$ nuclear magnetic resonance (NMR).

According to Ho et al., ${ }^{123}$ oversolubility could be due to: (1) more favorable interactions between solute and solid than between solvent and solid, favoring solute adsorption close to the pore walls; (2) the pore being partially filled, resulting in a gas-solvent interface; and (3) adsorption of the gas being favored in regions of low solvent densities due to layering. Gadikota et al. ${ }^{128}$ showed that solute size and the presence of salt in confined water are also important in modulating the dissolution of various gases in confined water. Using both experiments and simulations, these authors demonstrated greater solubility for $\mathrm{CO}_{2}$ and $\mathrm{Ar}$ in Na-montmorillonite compared to bulk water, whereas confinement reduced $\mathrm{CH}_{4}$. Gadikota et al. ${ }^{128}$ analyzed the contributions to the free energy of solvation due to cavity formation and affinity to the water-filled pore. The free energy change due to cavity formation was found to be generally positive (i.e. it introduces a barrier to solubility), while the enthalpic contribution is generally favorable to solubilization. Both effects depend on the size of the gas molecule.

Phan et al. ${ }^{129}$ revealed approximately one order of magnitude higher solubility of methane in water confined in a partially filled $1 \mathrm{~nm}$-wide silica pore. Methane molecules accumulated in narrow regions within the pores, where water molecular density was low. It was found that water molecules surrounding the guest methane were organized in hydrogen-bonded structures resembling gas hydrates. However, because of steric constraints, these clathrates were not stable. Phan et al. ${ }^{130}$ also considered other 1-nm slit-pore systems $\left(\mathrm{MgO}, \mathrm{Al}_{2} \mathrm{O}_{3}\right)$. The results demonstrated that methane solubility in confined water strongly depends on the confining material (Figure 12.8) because the molecular structure of confined water differs markedly within the three pore types. A direct correlation was observed between methane diffusion coefficients and water molecular density fluctuations. 

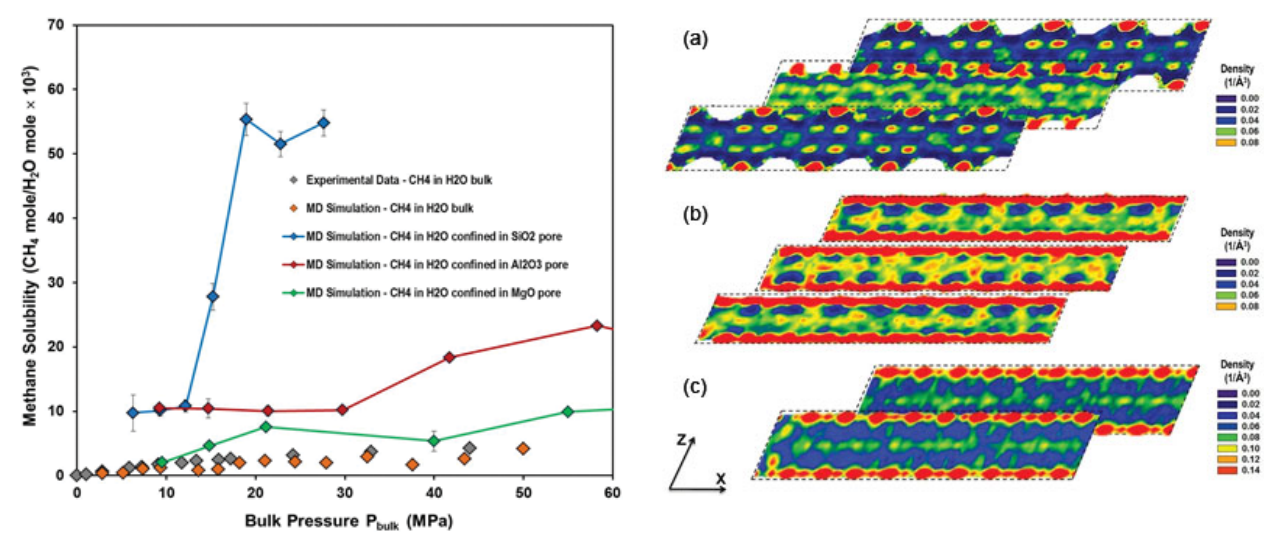

Figure 12.8 (Left) Methane solubility in confined water as a function of bulk pressure in $\mathrm{MPa}-\mathrm{SiO}_{2}$ blue, $\mathrm{Al}_{2} \mathrm{O}_{3}$ red, $\mathrm{MgO}$ green. Simulated bulk solubility of methane in liquid water at $298 \mathrm{~K}$ from Sakamaki et al. ${ }^{131}$ (Right) Variability for in-plane density distributions of water oxygen in layers parallel to the $\mathrm{x}-\mathrm{z}$ plane at several locations along the $\mathrm{y}$-axis within (a) $\mathrm{SiO}_{2}$, (b) $\mathrm{Al}_{2} \mathrm{O}_{3}$, and (c) $\mathrm{MgO}$. The results are for pores containing only water. Densities are expressed in number of molecules per cubic $\AA$.

Reprinted with permission from Phan A, Cole DR, Striolo A. Factors governing the behaviour of aqueous methane in narrow pores. Philos Trans A Math Phys Eng Sci 2015; 374: 20150019. ${ }^{130}$ Copyright and usage: the authors.

These observations are in contrast to those by Badmos et al., ${ }^{132}$ who estimated, using molecular dynamics, the solubility of $\mathrm{H}_{2} \mathrm{~S}$ in water confined in silica nanopores at $313 \mathrm{~K}$. The simulation results suggested that confinement reduces the $\mathrm{H}_{2} \mathrm{~S}$ solubility in water and that the solubility increases with increasing pore size. These results are due to perturbations on the coordination of water molecules around $\mathrm{H}_{2} \mathrm{~S}$ due to confinement. The perturbations are stronger in the narrowest pores considered. These results are qualitatively consistent with those reported for aqueous $\mathrm{NaCl}$ reported by Malani et al. ${ }^{133}$ This group reported a lower $\mathrm{NaCl}$ solubility in water confined within graphene nanopores. However, $\mathrm{NaCl}$ is a salt, and therefore it is likely that the mechanisms responsible for the reduced solubility of $\mathrm{H}_{2} \mathrm{~S}$ and $\mathrm{NaCl}$ in confined water are due to different interfacial processes.

The interest in geologic $\mathrm{CO}_{2}$ sequestration resulted in numerous studies on the form and movement of $\mathrm{CO}_{2}$ through porous networks, chiefly focusing on montmorillonite. Bowers et al. ${ }^{134}$ studied the incorporation of supercritical $\mathrm{CO}_{2}$ in smectite by in situ ${ }^{13} \mathrm{C}$ and ${ }^{23} \mathrm{Na}$ magic angle spinning NMR. They observed line broadening in the ${ }^{13} \mathrm{CO}_{2}$ resonance at $90^{\circ} \mathrm{C}$ and 50 bar $\mathrm{CO}_{2}$ pressure for Na-hectorite, consistent with $\mathrm{CO}_{2}$ pressure in the interlayers. Kirkpatrick et al. ${ }^{135}$ reviewed efforts using NMR and molecular modeling to explore mineral surfaces and interlayer filling by $\mathrm{H}_{2} \mathrm{O}$, cations, anions, $\mathrm{CO}_{2}$, and natural $\mathrm{OM}$ in swelling clays. In addition to entering the interlayer, there is evidence that $\mathrm{CO}_{2}$ dissolves in the confined water. Schaef et al. ${ }^{136}$ used NMR, x-ray diffraction and Monte Carlo simulation to explore the intercalation of dry supercritical $\mathrm{CO}_{2}$ into three swelling 
clays in which $\mathrm{Na}, \mathrm{NH}_{4}$, or Cs occupied the interlayer. In the absence of water, $\mathrm{CO}_{2}$ did enter the $\mathrm{NH}_{4}$ and Cs clays, but was excluded from the Na clay. A weak intercalation of $\mathrm{CH}_{4}$ has been observed for smectites, ${ }^{137}$ but is more pronounced for 4-nm weakly hydrated silica pores, as demonstrated by Ok et al. ${ }^{138}$

\subsubsection{Aqueous Electrolytes in Confinement}

The effect of nanoconfinement on the transport of aqueous electrolytes has been briefly summarized in Section 12.3.5. It is possible that, because confinement affects the structure and dynamics of confined water, it indirectly affects the solubility of electrolytes. For molecular simulations to reliably predict the properties of confined electrolytes, it is important that adequate force fields describe the interactions between water, electrolytes, and pore constituents, as well as all the cross-interactions between these components. ${ }^{139,140}$ The reliability of the force fields used to describe the electrolytes depends on the model chosen to simulate water, and it is essential to tune the ion-ion interactions if one seeks to replicate the experimental salt solubility. ${ }^{141,142}$ Svoboda and Lísal ${ }^{140}$ recently employed the grand canonical Monte Carlo algorithm to predict the solubility of $\mathrm{NaCl}$ in montmorillonite pores. The simulations were conducted at $365 \mathrm{~K}$ and 275 bar. At these conditions, the simulation models implemented (SPC/E model for water) predict a saturation $\mathrm{NaCl}$ concentration in water of $3.14 \mathrm{~mol} / \mathrm{kg},{ }^{139}$ which underestimates the experimental value of $6.1 \mathrm{~mol} / \mathrm{kg}$. ${ }^{143}$ The pore widths considered ranged from 1.0 to $3.2 \mathrm{~nm}$, and they were simulated in equilibrium with saturated bulk aqueous $\mathrm{NaCl}$ solutions. The results show that the concentrations of the adsorbed ions in the nanopores are lower than in the bulk aqueous system and decrease as the pore width narrows. Moucka et al. ${ }^{139}$ used simulations to compare the aqueous solubility of $\mathrm{NaCl}$ in Na-montmorillonite and pyrophyllite pores of the same width. They were able to distinguish the ionic solubility near the center of the pore, where the properties are similar to those found in bulk water, and those near the pore surfaces, where the properties are significantly different from those found in bulk water. As the pore width decreases, the contribution of the region near to the pore surface increases compared to that of the fluids near the pore center, and consequently the $\mathrm{NaCl}$ solubility strongly decreases compared to that observed in bulk water. In addition to structural effects, one could attempt to explain these observations based on the changes in the dielectric constant of water due to confinement, discussed below.

\subsubsection{Dielectric Constant of Nanoconfined Water}

The dielectric properties of water and electrolytes in nanopores are still poorly constrained for most substrates relevant to the subsurface. According to Renou et al., ${ }^{144}$ the static dielectric constant $(\varepsilon)$ characterizes the capacity of a material to transmit an electric field and controls the charge migration and dipole reorientation. Compared to other fluids types, bulk water has a high $\varepsilon$ due to the strong bonds between hydrogen and oxygen as well as 
hydrogen bonding between water molecules. This large $\varepsilon$ means that ionic substances tend to dissociate in water, yielding ionic solutions. Thus, the water $\varepsilon$ is essential to understanding the solvation of ions and their transport. For example, Sverjensky et al. ${ }^{145}$ extracted from the research of Pan et al. ${ }^{146}$ the theoretical estimates of the water dielectric constant at extreme pressures and temperatures to calculate the solubility of quartz and corundum to $600 \mathrm{MPa}$ and $1200^{\circ} \mathrm{C}$. This effort indicates that $\varepsilon$ ranges from as low as $\sim 2$ at $1200^{\circ} \mathrm{C}$ and 100 PMa to $\sim 80$ for ambient conditions.

Of interest to this chapter is how much of an effect nanoconfinement might have on $\varepsilon$, and further, how this change might impact mineral solubility. In confinement or near interfaces, $\varepsilon$ is no longer a simple scalar quantity, but it becomes tensorial. The radial component of water $\varepsilon_{\perp}$ is fundamentally important to the solvation and transport of ions, in contrast to the axial component $\left(\varepsilon_{11}\right)$, which is important for transport behavior along the pore wall. However, there are conflicting results with respect to the magnitude of the $\varepsilon$ values. For example, a number of MD studies have demonstrated a local interfacial increase in the axial (tangential) component of the dielectric constant $\left(\varepsilon_{11}\right)$ relative to the bulk water value and to values exhibited by the radial $\varepsilon_{\perp} \cdot{ }^{147-149}$ An enhanced $\varepsilon_{11}$ was also predicted in other studies that addressed the role of cylindrical silica and carbon nanopores. ${ }^{144,149-151}$ Conversely, values for the radial $\varepsilon_{\perp}$ tend to be equal to or much less than the bulk $\varepsilon$. This anisotropy is most pronounced in hydrophobic pores.

Unlike the increase of the axial dielectric permittivity near the pore wall noted above, Renou et al. ${ }^{144}$ observed a significant decrease in $\varepsilon_{11}$ relative to the ambient bulk water value with increasing surface charge density using MD. More recently, Fumagalli et al. ${ }^{152}$ observed anomalously low $\varepsilon$ (approaching 1) of confined water that was two to three molecules thick in dielectric imaging experiments involving graphene and boron nitrite. Similarly, Zhu et al. ${ }^{153}$ reported on the anomalous behavior of $\varepsilon$ for aqueous solutions of $\mathrm{NaCl}$ of varying concentration $(0-1.5 \mathrm{M})$ confined in a 2.4-nm diameter cylindrical silica pore (Figure 12.9). They noted that the dielectric constant profile near the surface correlates with that of the water density. Using classical MD simulations, Zhu et al. ${ }^{153}$ demonstrated: (1) a marked anisotropy between $\varepsilon_{11}$ and $\varepsilon_{\perp}$; (2) that the values for $\varepsilon_{11}$ decrease relative to those of pure water, but show enhancement near the pore wall; and (3) that $\varepsilon_{\perp}$ shows a nonlinear $\mathrm{NaCl}$ concentration dependency. Renou et al. ${ }^{154}$ addressed the structural and dielectric behavior of confined $\mathrm{NaCl}, \mathrm{NaI}, \mathrm{MgCl}_{2}$, and $\mathrm{Na}_{2} \mathrm{SO}_{4}$ (1 $\mathrm{M}$ concentration) in nanoporous hydrophilic 1.2-nm silica pores. They also reported a dielectric anisotropy of confined water and an unusual increase in the radial component of permittivity $\left(\varepsilon_{\perp}\right)$ of confined solutions.

It is notable that the range of dielectric constant values reported for water confined in nanopores encompasses the range of $\varepsilon$ values estimated for bulk water from ambient to extreme conditions. This suggests the distinct possibility that the bulk values for $\varepsilon$ currently used to estimate fluid properties in the subsurface might not be appropriate, especially for pores such as those illustrated in Figures 12.2 and 12.3. We lack a comprehensive assessment of $\varepsilon$ for nanoconfined environments relevant to subsurface conditions (i.e. at elevated pressure and temperature with widely varying solution compositions) and 


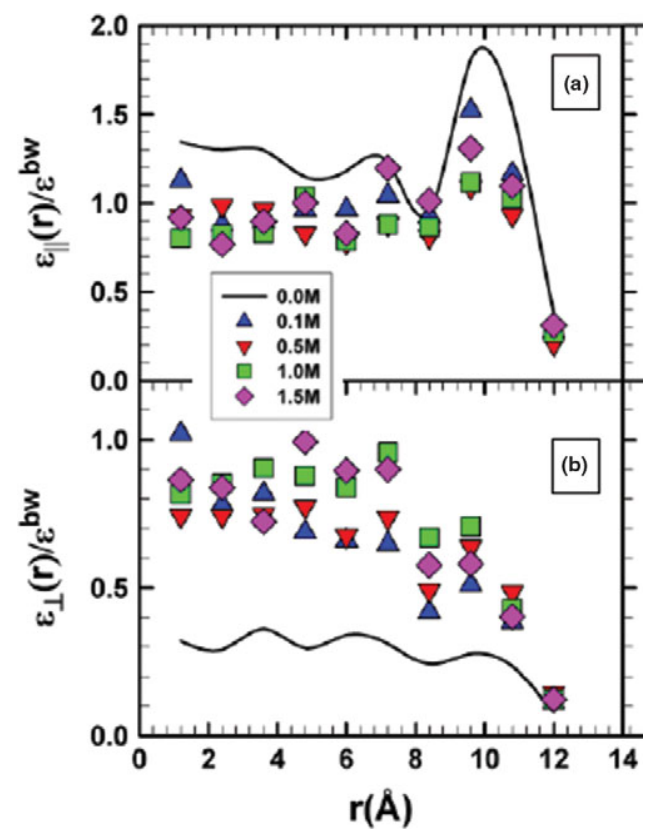

Figure 12.9 Profiles of the ratios of $\varepsilon_{11}$ (a) and $\varepsilon_{\perp}$ (b) for $\mathrm{NaCl}$ solutions of varying concentrations confined in 2.4-nm diameter cylindrical $\mathrm{SiO}_{2}$ pores to the dielectric constant of bulk water $\left(\varepsilon^{\mathrm{bw}}\right)$. Reprinted with permission from Zhu H, Ghoufi A, Szymczyk A, Balannec B, Morineau D. Anomalous dielectric behavior of nanoconfined electrolytic solutions. Phys Rev Lett 2012; 109: 107801. ${ }^{153}$ Copyright 2012 American Physical Society.

a quantification of whether these "local" effects yield important consequences on, for example, salt solubility and other important observables.

\subsection{Form and Origin: Confinement Effects on Reactivity}

\subsubsection{General Concept}

In this section, we address the reactivity of carbon-bearing fluids and how confinement can affect their behavior. Based on thermodynamic arguments, Shock ${ }^{155}$ predicted that, in the subsurface, the most common form of fluid carbon would be that of $\mathrm{CO}_{2}$, not $\mathrm{CH}_{4}$. This prediction was based on the analysis of the thermodynamic equilibrium of the reaction:

$$
\mathrm{CO}_{2}+4 \mathrm{H}_{2} \leftrightarrow \mathrm{CH}_{4}+2 \mathrm{H}_{2} \mathrm{O} .
$$

The equilibrium was assessed based on the expected $\mathrm{pH}$ as buffered by the rocks. However, nanoconfinement could potentially affect fluid reactivity via three main mechanisms: (1) the closeness of the rock surfaces provides catalytic sites that speed up some reaction pathways, thus affecting the kinetics of the reactions; (2) the confinement is so 
restrictive that some of the reactants or the products are either not able to react or are not allowed to escape from the porous matrix; and (3) the preferential adsorption of some of the fluid components onto the rock surface can affect the overall equilibrium composition via a molecular-level application of Le Chatelier's principle. The first of these three scenarios concerns kinetic effects. We only note that some olivines contain $\mathrm{Ni}, \mathrm{Co}$, and/ or $\mathrm{Cr}$, which could act as catalysts to increase the rate of chemical reactions, including the oxidation of $\mathrm{CH}_{4}$ to $\mathrm{CO}_{2}{ }^{156}$

\subsubsection{Methanation of Carbon Dioxide}

Using reactive ensemble Monte Carlo simulation, Le et al. ${ }^{157}$ explored whether confinement could alter the bulk expectations regarding reaction (12.2). In particular, they tested whether the preferential adsorption of either $\mathrm{CO}_{2}$ or $\mathrm{H}_{2} \mathrm{O}$ on the pore surface could affect the equilibrium conversion of $\mathrm{CO}_{2}$ to $\mathrm{CH}_{4}$. The system simulated represented a nanoporous matrix in contact with a larger microfracture occupied by the bulk fluid. Water, hydrogen, carbon dioxide, and methane were free to exchange between the nanopores and the microfracture and to react within the various environments. The microfracture was large enough to provide a "bulk" system. The conceptual framework is summarized in Figure 12.10 .

Le et al. ${ }^{157}$ generated slit-shaped pores ( 1 and $2 \mathrm{~nm}$ ) carved out of $\beta$-cristobalite silica. The results showed that the thermodynamic equilibrium composition shifted toward methane production, suggesting that thermal hydrocarbon synthesis near hydrothermal

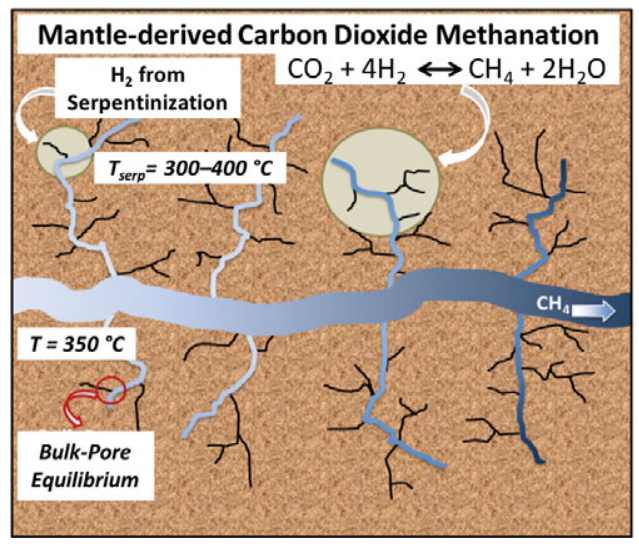

Figure 12.10 Schematic for a possible carbon dioxide methanation process. Within oceanic crust, mantle-derived melt is emplaced at shallow depths and heats the ultramafic ocean crust driving seawater circulation along natural fractures and microfractures where serpentinization reactions take place. The $\mathrm{H}_{2}$ produced could come into contact with carbon dioxide derived from the mantle.

Reprinted with permission from Le T, Striolo A, Turner CH, Cole DR. Confinement effects on carbon dioxide methanation: a novel mechanism for abiotic methane formation. Sci Rep 2017; 7: $9021 .{ }^{157}$ 


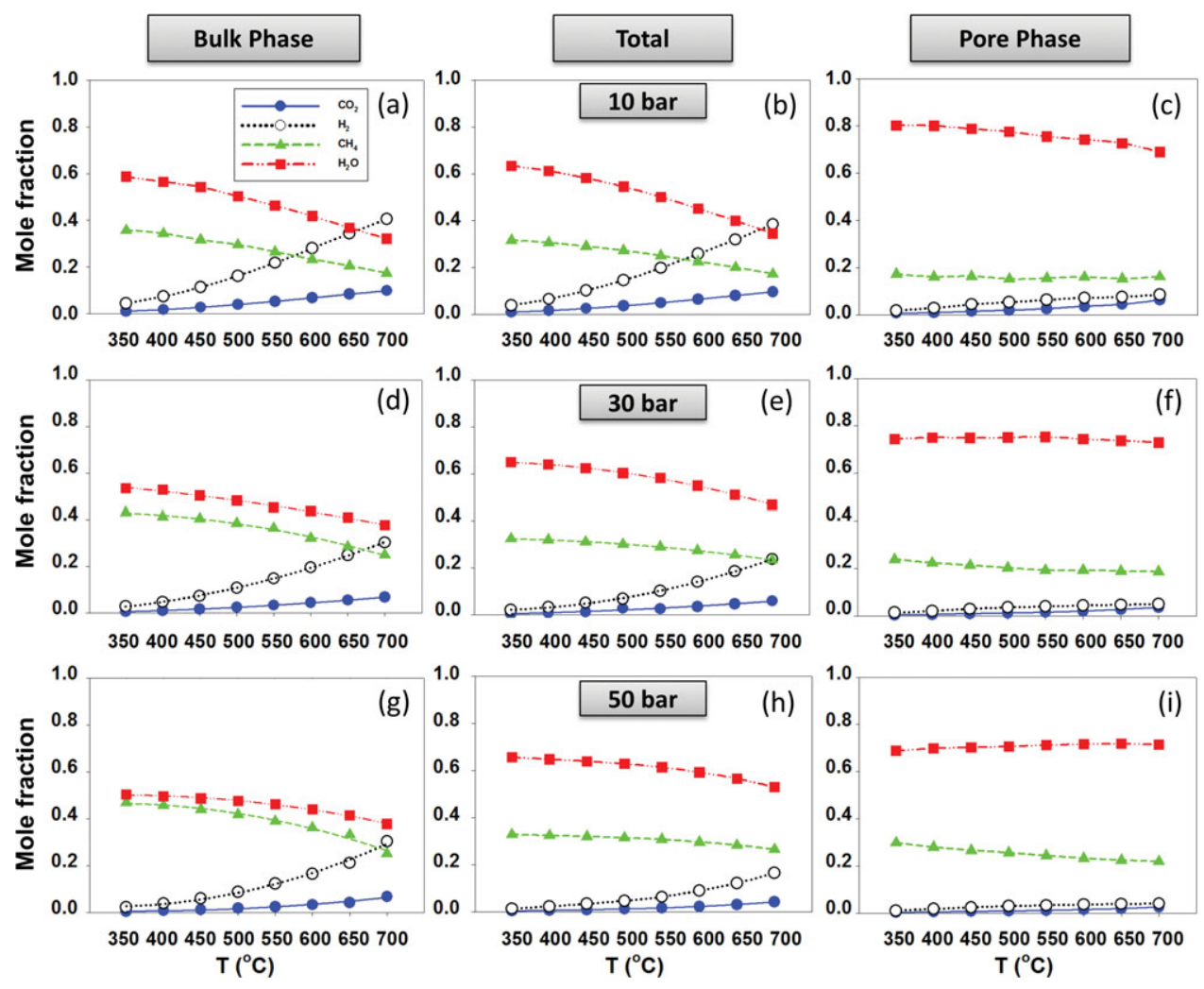

Figure 12.11 Product fraction of $\mathrm{CO}_{2}$ methanation (reaction (12.1)) for the (a, d, and g) bulk phase and (c, f, and i) pore phase in equilibrium with each other at different temperatures and pressures. (b), (e), and (h) show total molecular fractions.

Reprinted with permission from Le T, Striolo A, Turner CH, Cole DR. Confinement effects on carbon dioxide methanation: a novel mechanism for abiotic methane formation. Sci Rep 2017; 7: $9021{ }^{157}$

vents and deeper in the magma-hydrothermal system is possible. The results showed strong dependency of the reaction equilibrium conversions, $X_{\mathrm{CO}_{2}}$, on nanopore size, nanopore chemistry, and nanopore morphology. All conditions that enhance water adsorption (i.e. increasing pore hydrophilicity or surface roughness) resulted in an enhancement of reaction yield. Representative results for 1-nm pores are shown in Figure 12.11, where the composition in the bulk phase (left-hand panels) is compared to that within the pores (right-hand panels). In situations in which the pore space is dominant compared to the bulk space, it is conceivable that the overall system composition strongly deviates from bulk expectations.

These results could contribute to an important scientific debate focusing on the possibility of the abiotic synthesis of hydrocarbons during oceanic crust-seawater interactions, which could reshape the core hypotheses of the origin of life. ${ }^{158,159}$ 


\subsection{Summary and Opportunities}

Exploring the behavior of complex geofluids confined in micro- and meso-porous networks provides the foundation for quantifying geologically relevant systems where mass and energy exchange occur. Nanoconfinement in porous systems gives rise to rich behavior that results from the interplay of geometrical restriction imposed by different pore features (size, geometry, chemical composition, etc.), the interaction between the porous material and the fluid, and the nature of the confined fluid itself. Fluid structure (or "form") affects most if not all fundamental properties of interest. Since nanopores affect structure, they impact movement, reactivity ("origin"), and quantity. While in relatively large mesopores fluid "movement" might occur at different timescales as a function of location in the pore, greater geometric confinement can lead to severely constrained motion, such as the molecular diffusion mechanisms discussed in Section 12.3. Within a given porous matrix, timescales of motion of confined fluids can exhibit interesting dependencies on the molecular size and concentration of the confining fluid, such as the levitation effect of confined hydrocarbons or anomalous pressure dependence on gas dynamics in mesoporous media.

Water and associated dissolved constituents, as a confined fluid, exhibit very rich structural and dynamical behavior due to the effects of hydrogen bonding, compounded by the other effects identified above. All of these effects lead to a wide variety of length and time scales relevant to the study of confined fluids and as such require a variety of experimental and computational tools for a thorough study of the behavior of geologically relevant confined fluids. The techniques that probe the behavior of confined fluids at the molecular level depend heavily on the interpretation of the measured data and as such can be prone to subjective bias. Therefore, if possible, it is advantageous to look at each solidfluid system from different perspectives, both experimental and computational. Much progress is expected when synergistic approaches are implemented. For example, one obvious next step would be the detailed experimental and computational investigation of the structural properties of fluid mixtures in increasingly realistic systems. This includes complex fluid mixtures, as well as porous materials that are heterogeneous and better representative of the subsurface. Once these analyses are obtained, one should challenge the mechanisms discussed in Sections 12.3 and 12.4. A second target of opportunity pertains to whether the presence of ions and associated hydration affect the transport and accumulation of hydrocarbons in nanoporous matrices. The presence of concentrated salts disrupts water structure, slows down its dynamics, and alters the water free energy landscape, which impacts transport of guest molecules. ${ }^{106,130}$ Clearly, how one fluid component invades and displaces and/or competes with another for surface sites will have a profound effect on these types of transport mechanisms. The dielectric properties of water and aqueous systems under nanoconfinement are poorly constrained for Earth-relevant systems. Recent studies have exhibited a wide range of values that are not always in agreement. 
Finally, we point to the effects of confinement on the equilibrium composition of reactive systems. The results summarized in Section 12.5 suggest that thermogenic methane production could be enhanced by nanoconfinement, albeit within a specific window of pressure-temperature-composition conditions. To quantify whether those simulation results are relevant across a broader temperature and pressure landscape, a few research questions remain to be addressed, in particular:

1. Will the $\mathrm{CO}_{2}$ methanation reaction encounter kinetic barriers within the pores or will the pore surfaces provide active sites for catalyzing the reaction?

2. How much nanopore volume in the subsurface is needed for achieving levels of methane production that are relevant for hydrocarbons synthesis?

3. Can these insights be reproduced by experiments?

Future studies could be implemented to address these and related questions and to quantify how these phenomena affect the carbon cycle.

\section{Acknowledgments}

AS acknowledges financial support from the European Union via the Marie Curie Career Integration Grant No. 2013-CIG-631435, as well as from the European Union's Horizon 2020 research and innovation program under Grant No. 640979 and Grant No. 764810. DC was supported by the US Department of Energy, Office of Basic Energy Sciences, Division of Chemical Sciences, Geosciences and Biosciences under grant DE-SC0006878. DC and AS both receive partial funding from the Sloan Foundation-funded Deep Carbon Observatory. Special thanks to Ms. Tran Le for her help in assembling the reference list.

\section{Questions for the Classroom}

1. Are nanopores observed in all Earth materials? How are these observed? What are their shapes, sizes, and distributions? Is there a correlation between these properties and depth?

2. Discuss quantitatively how confinement affects the thermophysical properties of a fluid, whether pure or a mixture. Discuss the effects due to strong pore-fluid interactions and how changing the pore width affects these outcomes. Discuss in particular such effects with respect to solubility, reactivity, phase equilibria, and melting.

3. Discuss the differences between surface and pore diffusion. What are the mechanisms responsible for each and when is surface diffusion expected to dominate over pore diffusion in determining the overall fluid transport across a porous material? What mechanisms become dominant as the pore size becomes comparable to the size of a fluid molecule?

4. How does the presence of a pore affect the reactivity of a fluid? Distinguish between kinetic and thermodynamic effects. 


\section{References}

1. Anovitz LM, Cole DR. Characterization and analysis of porosity and pore structures. Rev Mineral Geochem 2015; 80: 61-164.

2. Keller LM, Holzer L, Wepf R, Gasser P. 3D geometry and topology of pore pathways in Opalinus clay: implications for mass transport. Appl Clay Sci 2011; 52: 85-95.

3. Keller LM, Schuetz P, Erni R, Rossell MD, Lucas F, Gasser P et al. Characterization of multi-scale microstructural features in Opalinus clay. Microporous Mesoporous Matter 2013; 170: 83-94.

4. Mehmani Y, Balhoff MT. Mesoscale and hybrid models of fluid flow and solute transport. Rev Mineral Geochem 2015; 80: 433-459.

5. Peth S, Horn R, Beckmann F, Donath T, Fischer J, Smucker AJM. Three-dimensional quantification of intra-aggregate pore-space features using synchrotronradiation-based microtomography. Soil Sci Soc Am J 2008; 72: 897-907.

6. Landrot G, Ajo-Franklin JB, Yang L, Cabrini S, Steefel CI. Measurement of accessible reactive surface area in a sandstone, with application to $\mathrm{CO}_{2}$ mineralization. Chem Geol 2012; 318: 113-125.

7. Peters CA. Accessibilities of reactive minerals in consolidated sedimentary rock: an imaging study of three sandstones. Chem Geol 2009; 265: 198-208.

8. Beckingham LE, Mitnick EH, Steefel CI, Zhang S, Voltolini M, Swift AM et al. Evaluation of mineral reactive surface area estimates for prediction of reactivity of a multi-mineral sediment. Geochim Cosmochim Acta 2016; 188: 310-329.

9. Bernabe Y, Li M, Maineult A. Permeability and pore connectivity: a new model based on network simulations. J Geophys Res 2010; 115: B10203.

10. Ewing RP, Liu CX, Hu QH. Modeling intragranular diffusion in low-connectivity granular media. Water Resour Res 2012; 48: W03518.

11. Keller LM, Holzer L, Wepf R, Gasser P, Munch B, Marschall P. On the application of focused ion beam nanotomography in characterizing the 3D pore space geometry of Opalinus clay. Phys Chem Earth 2011; 36: 1539-1544.

12. Lindquist WB, Venkatarangan A, Dunsmuir J, Wong TF. Pore and throat size distributions measured from synchrotron X-ray tomographic images of Fontainebleau sandstones. J Geophys Res Solid Earth 2000; 105: 21509-21527.

13. Hay MB, Stoliker DL, Davis JA, Zachara JM. Characterization of the intragranular water regime within subsurface sediments: pore volume, surface area, and mass transfer limitations. Water Resour Res 2011; 47: W10531.

14. Dultz S, Simonyan AV, Pastrana J, Behrens H, Plotze M, Rath T. Implications of pore space characteristics on diffusive transport in basalts and granites. Environ Earth Sci 2013; 69: 969-985.

15. Navarre-Sitchler A, Steefel CI, Yang L, Tomutsa L, Brantley SL. Evolution of porosity and diffusivity associated with chemical weathering of a basalt clast. J Geophys Res 2009; 114: F02016.

16. Polak A, Elsworth D, Yasuhara H, Grader AS, Halleck PM. Permeability reduction of a natural fracture under net dissolution by hydrothermal fluids. Geophys Res Lett 2003; 30: 2020.

17. Stack AG, Fernandez-Martinez A, Allard LF, Banuelos JL, Rother G, Anovitz LM et al. Pore-size-dependent calcium carbonate precipitation controlled by surface chemistry. Environ Sci Technol 2014; 48: 6177-6183.

18. DePaolo DJ, Cole DR. Geochemistry of geologic carbon sequestration: an overview. Rev Mineral Geochem 2013; 77: 1-14. 
19. Steefel CI, DePaolo DJ, Lichtner PC. Reactive transport modeling: an essential tool and a new research approach for the Earth sciences. Earth Planet Sci Lett 2005; 240: $539-558$.

20. Steefel CI, Molins S, Trebotich D. Pore scale processes associated with subsurface $\mathrm{CO}_{2}$ injection and sequestration. Rev Mineral Geochem 2013; 77: 259-303.

21. Tokunaga TK, Wan JM. Capillary pressure and mineral wettability influences on reservoir $\mathrm{CO}_{2}$ capacity. Rev Mineral Geochem 2013; 77: 481-503.

22. Cole DR, Ok S, Striolo A, Anh P. Hydrocarbon behavior at nanoscale interfaces. Rev Mineral Geochem 2013; 75: 495-545.

23. Stack AG. Precipitation in pores: a geochemical frontier. Rev Mineral Geochem 2015; 80: 165-190.

24. Zachara J, Brantley S, Chorover J, Ewing R, Kerisit S, Liu CX et al. Internal domains of natural porous media revealed: critical locations for transport, storage, and chemical reaction. Environ Sci Technol 2016; 50: 2811-2829.

25. Mehmani A, Mehmani Y, Prodanovic M, Balhoff M. A forward analysis on the applicability of tracer breakthrough profiles in revealing the pore structure of tight gas sandstone and carbonate rocks. Water Resour Res 2015; 51: 4751-4767.

26. Steefel CI, Appelo CAJ, Arora B, Jacques D, Kalbacher T, Kolditz O et al. Reactive transport codes for subsurface environmental simulation. Comput Geosci 2015; 19: 445-478.

27. DiCarlo DA, Aminzadeh B, Roberts M, Chung DH, Bryant SL, Huh C. Mobility control through spontaneous formation of nanoparticle stabilized emulsions. Geophys Res Lett 2011; 38: L24404.

28. DiCarlo D, Aminzadeh B, Chung DH, Roberts M, Huh C, Bryant SL. Effect of nanoparticles on the displacement pattern of $\mathrm{CO}_{2}$ injection in porous media. Presented at: Goldschmidt Conference, Session 275, 2012.

29. Bryant S, Yu H, Murphy M, Zhang T, Worthen, Yoon KY et al. Mechanisms governing nanoparticle transport in porous media. Presented at: Goldschmidt Conference, Session 275, 2012.

30. Ramanan B, Holmes WM, Sloan WT, Phoenix VR. Investigation of nanoparticle transport inside coarse-grained geological media using magnetic resonance imaging. Environ Sci Technol 2012; 46: 360-366.

31. Phoenix V, Lakshmanan S, Sloan W, Holmes WM. Opening the black box: imaging nanoparticle transport through rock with MRI. Presented at: Goldschmidt Conference, Session 172, 2012.

32. Deutch J, Moniz EJ. The Future of Coal: Options for a Carbon-Constrained World. An Interdisciplinary MIT Study. Cambridge, MA: Massachusetts Institute of Technology, 2007.

33. Titley SR, ed. Evolution and Style of Fracture Permeability in Intrusive-Centered Hydrothermal Systems. Washington, DC: National Academic Press, 1990, pp. 50-63.

34. Ingebritsen SE, Sanford WE, eds. Groundwater in Geologic Processes. Cambridge: Cambridge University Press, 1998.

35. Laubach SE, Ward ME. Diagenesis in porosity evolution of opening-mode fractures, Middle Triassic to Lower Jurassic La Boca Formation, NE Mexico. Tectonophysics 2006; 419: 75-97.

36. Laubach SE, Reed RM, Olson JE, Lander RH, Bonnell LM. Coevolution of crackseal texture and fracture porosity in sedimentary rocks: cathodoluminescence observations of regional fractures. J Struct Geol 2004; 26: 967-982. 
37. Gale JFW, Lander RH, Reed RM, Laubach SE. Modeling fracture porosity evolution in dolostone. J Struct Geol 2010; 32: 1201-1211.

38. Ague JJ, ed. Fluid Flow in the Deep Crust. Oxford: Elsevier, 2014, pp. 203-247.

39. Norton D, Knapp R. Transport phenomena in hydrothermal systems: the nature of porosity. Am J Sci 1977; 277: 913-936.

40. Petford N, Koenders MA. Shear-induced pressure changes and seepage phenomena in a deforming porous layer - I. Geophys J Int 2003; 155: 857-869.

41. Marquardt K, Faul UH. The structure and composition of olivine grain boundaries: 40 years of studies, status and current developments. Phys Chem Miner 2018; 45: 139-172.

42. Rother G, Krukowski EG, Wallacher D, Grimm N, Bodnar RJ, Cole DR. Pore size effects on the sorption of supercritical $\mathrm{CO}_{2}$ in mesoporous CPG-10 Silica. J Phys Chem C 2012; 116: 917-922.

43. Phan A, Cole DR, Striolo A. Liquid ethanol simulated on crystalline alpha alumina. J Phys Chem B 2013; 117: 3829-3840.

44. Phan A, Cole DR, Striolo A. Preferential adsorption from liquid water-ethanol mixtures in alumina pores. Langmuir 2014; 30: 8066-8077.

45. Gubbins KE, Long Y, Sliwinska-Bartkowiak M. Thermodynamics of confined nanophases. J Chem Thermodyn 2014; 74: 169-183.

46. Firincioglu T, Ozkan E, Ozgen C. Thermodynamics of multiphase flow in unconventional liquids-rich reservoirs. Presented at: SPE Annual Technical Conference and Exhibition Society of Petroleum Engineers, 2012.

47. Wu Y-S. Multiphase Fluid Flow in Porous and Fractured Reservoirs. Houston, TX: Gulf Professional Publishing, 2015.

48. Teklu TW, Alharthy N, Kazemi H, Yin XL, Graves RM, AlSumaiti AM. Phase behavior and minimum miscibilitypressure in nanopores. Spec Reserv Eval Eng 2014; 17: 396-403.

49. Akkutlu IY, Rahmani DB. SPE International Symposium on Oilfield Chemistry. Richardson, TX: Society of Petroleum Engineers, 2013.

50. Striolo A. Understanding interfacial water and its role in practical applications using molecular simulations. MRS Bull 2014; 39: 1062-1068.

51. Clarkson CR, Haghshenas B, Ghanizadeh A, Qanbari F, Williams-Kovacs JD, Riazi $\mathrm{N}$ et al. Nanopores to megafractures: current challenges and methods for shale gas reservoir and hydraulic fracture characterization. J Nat Gas Sci Eng 2016; 31: 612-657.

52. Ho TA, Criscenti LJ, Wang YF. Nanostructural control of methane release in kerogen and its implications to wellbore production decline. Sci Rep 2016; 6: 28053.

53. Ferreira DR, Schulthess CP, Giotto MV. An investigation of strong sodium retention mechanisms in nanopore environments using nuclear magnetic resonance spectroscopy. Environ Sci Technol 2012; 46: 300-306.

54. Turner DD, Ferrare RA, Brasseur LAH, Feltz WF. Automated retrievals of water vapor and aerosol profiles from an operational Raman lidar. J Atmos Ocean Technol 2002; 19: 37-50.

55. Turner CH, Brennan JK, Lisal M, Smith WR, Johnson JK, Gubbins KE. Simulation of chemical reaction equilibria by the reaction ensemble Monte Carlo method: a review. Mol Simulat 2008; 34: 119-146.

56. Santiso E, Firoozabadi A. Curvature dependency of surface tension in multicomponent systems. AIChE J 2005; 52: 311-322. 
57. Abbas M, Nadeem R, Zafar MN, Arshad M. Biosorption of chromium (III) and chromium (VI) by untreated and pretreated Cassia fistula biomass from aqueous solutions. Water Air Soil Pollut 2008; 191: 139-148.

58. Beckingham LE, Steefel CI, Swift AM, Voltolini M, Yang L, Anovitz LM et al. Evaluation of accessible mineral surface areas for improved prediction of mineral reaction rates in porous media. Geochim Cosmochim Acta 2017; 205: 31-49.

59. Allen MP, Tildesley DJ, eds. Computer Simulation of Liquids. Oxford: Oxford University Press, 2017.

60. Marx D, Hutter J, eds. Ab Initio Molecular Dynamics, Basic Theory and Advanced Methods. Cambridge: Cambridge University Press, 2009.

61. Frenkel D, Smit B, eds. Understanding Molecular Simulation. Amsterdam: Elsevier, 2001.

62. Brovchenko I, Oleinikova A. Which properties of a spanning network of hydration water enable biological functions? Chemphyschem 2008; 9: 2695-2702.

63. Striolo A, Michaelides A, Joly L. The carbon-water interface: modeling challenges and opportunities for the water-energy nexus. Annu Rev Chem Biomol Eng 2016; 7: 533-556.

64. Senftle TP, Hong S, Islam MM, Kylasa SB, Zheng YX, Shin YK et al. The ReaxFF reactive force-field: development, applications and future directions. NPJ Comput Mater 2016; 2: 15011.

65. Fenter P, Sturchio NC. Mineral-water interfacial structures revealed by synchrotron X-ray scattering. Prog Surf Sci 2004; 77: 171-258.

66. Cole DR, Herwig K, Mamontov E, Larese LZ. Neutron scattering and diffraction studies of fluids and fluid-solid interactions. In: Wenk H-R, ed. Neutron Scattering in Earth Science, Reviews in Mineralogy and Geochemistry, Vol. 63. Chantilly, VA: Mineralogical Society of America, 2006, pp. 313-362.

67. Cole DR, Mamontov E, Rother G. Structure and dynamics of fluids in microporous and mesoporous earth and engineered materials. In: Liang L, Rinaldi R, Schober H, eds. Neutron Applications in Earth, Energy, and Environmental Sciences. Berlin: Springer, 2009, pp. 547-570.

68. Karger J, Ruthven DM, Theodorou DN, eds. Diffusion in Nanoporous Materials. Hoboken, NJ: Wiley, 2012.

69. Melnichenko Y, ed. Small-Angle Scattering from Confined and Interfacial Fluids. Applications to Energy Storage and Environmental Fluids. Berlin: Springer, 2016.

70. Gautam S. Use of quasielastic neutron scattering and molecular dynamics simulation to study molecular dynamics under confinement. In: Reimer A, ed. Horizons in World Physics Vol. 290. New York: Nova Science Publishers, 2017, pp. 25-44.

71. Gautam S, Le T, Striolo A, Cole D. Molecular dynamics simulations of propane in slit shaped silica nano-pores: direct comparison with quasielastic neutron scattering experiments. Phys Chem Chem Phys 2017; 19: 32320-32332.

72. Nelson PH. Permeability-porosity relationships in sedimentary rocks. Log Anal 1994; 35: 38-62.

73. Ingebritsen SE, Sanford WE, Neuzil CE, eds. Groundwater in Geologic Processes. Cambridge: Cambridge University Press, 2006.

74. Gleeson T, Ingebritsen SE, ed. Introduction. In Crustal Permeability. Hoboken, NJ: Wiley, 2017, pp. 1-5.

75. Lockner DA, Byerlee JD, Kuksenko V, Ponomarev A, Sidorin A. Quasi-static fault growth and shear fracture energy in granite. Nature 1991; 350: 39-42. 
76. Ingebritsen SE, Manning CE. Geological implications of a permeability-depth curve for the continental crust. Geology 1999; 27: 1107-1110.

77. Ingebritsen SE, Manning CE. Diffuse fluid flux through orogenic belts: implications for the world ocean. Proc Natl Acad Sci USA 2002; 99: 9113-9116.

78. Ingebritsen SE, Manning CE. Permeability of the continental crust: dynamic variations inferred from seismicity and metamorphism. Geofluids 2010; 10: 193-205.

79. Bredehoeft JD, Norton DL. Mass and energy transport in a deforming Earth's crust. In: The Role of Fluids in Crustal Processes. Washington, DC: National Academy Press, 1990. pp. 27-41.

80. Anovitz LM, Cole DR, Jackson AJ, Rother G, Littrell KC, Allard LF et al. Effect of quartz overgrowth precipitation on the multiscale porosity of sandstone: a (U)SANS and imaging analysis. Geochim Cosmochim Acta 2015; 158: 199-222.

81. Anovitz LM, Cole DR. Analysis of the pore structures of shale using neutron and Xray small-angle scattering. In: Vialle S, Ajo-Franklin J, Carey W, eds. Geological Carbon Storage: Subsurface Seals and Caprock, Hoboken, NJ: Wiley, 2018, pp. 71-119.

82. Wark DA, Watson EB. Grain-scale permeabilities of texturally equilibrated, monomineralic rocks. Earth Planet Sci Lett 1998; 164: 591-605.

83. Cole DR, Chakraborty S. Rates and mechanisms of isotopic exchange. Rev Mineral Geochem 2001; 43: 83-223.

84. Watson EB, Baxter EF. Diffusion in solid-Earth systems. Earth Planet Sci Lett 2007; 253: 307-327.

85. Farver JR. Oxygen and hydrogen diffusion in minerals. Rev Mineral Geochem 2010; 72: 447-507.

86. Wirth R. Thin amorphous films $(1-2 \mathrm{~nm})$ at olivine grain boundaries in mantle xenoliths from San Carlos, Arizona. Contrib Mineral Petrol 1996; 124: 44-54.

87. Gelb LD, Gubbins KE, Radhakrishnan R, Sliwinska-Bartkowiak M. Phase separation in confined systems. Rep Prog Phys 1999; 62: 1573-1659.

88. Radhakrishnan R, Gubbins KE, Sliwinska-Bartkowiak M. Global phase diagrams for freezing in porous media. $J$ Chem Phys 2002; 116: 1147-1155.

89. Alba-Simionesco C, Coasne B, Dosseh G, Dudziak G, Gubbins KE, Radhakrishnan $\mathrm{R}$ et al. Effects of confinement on freezing and melting. J Phys Condens Matter 2006; 18: R15-R68.

90. Wang J, Kalinichev AG, Kirkpatrick RJ. Molecular modeling of the 10- $\AA$ phase at subduction zone conditions. Earth Planet Sci Lett 2004; 222: 517-527.

91. Wang JW, Kalinichev AG, Kirkpatrick RJ. Structure and decompression melting of a novel, high-pressure nanoconfined 2-D ice. J Phys Chem B 2005; 109: 14308-14313.

92. Radhakrishnan R, Gubbins KE, Sliwinska-Bartkowiak M. Existence of a hexatic phase in porous media. Phys Rev Lett 2002; 89: 076101.

93. Gallo P, Arnann-Winkel K, Angell CA, Anisimov MA, Caupin F, Chakravarty C et al. Water: a tale of two liquids. Chem Rev 2016; 116: 7463-7500.

94. Chiavazzo E, Fasano M, Asinari P, Decuzzi P. Scaling behaviour for the water transport in nanoconfined geometries. Nat Commun 2014; 5: 3565.

95. Ho TA, Papavassiliou DV, Lee LL, Striolo A. Liquid water can slip on a hydrophilic surface. Proc Natl Acad Sci USA 2011; 108: 16170-16175.

96. Kim HJ, Brunelli NA, Brown AJ, Jang KS, Kim WG, Rashidi F et al. Silylated mesoporous silica membranes on polymeric hollow fiber supports: synthesis and permeation properties. ACS Appl Mater Interfaces 2014; 6: 17877-17886. 
97. Ge Q, Wang Z, Yan Y. High-performance zeolite NaA membranes on polymerzeolite composite hollow fiber supports. J Am Chem Soc 2009; 131: 17056-17057.

98. Patankar S, Gautam S, Rother G, Podlesnyak A, Ehlers G, Liu T et al. Role of confinement on adsorption and dynamics of ethane and an ethane- $\mathrm{CO}_{2}$ mixture in mesoporous CPG silica. J Phys Chem C 2016; 120: 4843-4853.

99. Le T, Striolo A, Cole DR. $\mathrm{CO}_{2}-\mathrm{C}_{4} \mathrm{H}_{10}$ mixtures simulated in silica slit pores: relation between structure and dynamics. J Phys Chem C 2015; 119: 15274-15284.

100. Le T, Ogbe S, Striolo A, Cole DR. N-octane diffusivity enhancement via carbon dioxide in silica slit-shaped nanopores - a molecular dynamics simulation. Mol Simulat 2016; 42: 745-752.

101. Gautam S, Liu TT, Rother G, Jalarvo N, Mamontov E, Welch S et al. Dynamics of propane in nanoporous silica aerogel: a quasielastic neutron scattering study. $J$ Phys Chem C 2015; 119: 18188-18195.

102. Chathoth SM, He L, Mamontov E, Melnichenko YB. Effect of carbon dioxide and nitrogen on the diffusivity of methane confined in nano-porous carbon aerogel. Microporous Mesoporous Matter 2012; 148: 101-106.

103. Gautam S, Jalarvo N, Rother G, Liu T, Mamontov E, Dai S et al. Quasieleastic neutron scattering studies on propane in nanoporous silica. Presented at: German Conference on Neutron Scattering, 2016.

104. Le TTB, Striolo A, Gautam SS, Cole DR. Propane-water mixtures confined within cylindrical silica nanopores: structural and dynamical properties probed by molecular dynamics. Langmuir 2017; 33: 11310-11320.

105. Ho TA, Striolo A. Water and methane in shale rocks: flow pattern effects on fluid transport and pore structure. AIChE J 2015; 61: 2993-2999.

106. Phan A, Cole DR, Weiss RG, Dzubiella J, Striolo A. Confined water determines transport properties of guest molecules in narrow pores. ACS Nano 2016; 10: 7646-7656.

107. Bui T, Phan A, Cole DR, Striolo A. Transport mechanism of guest methane in waterfilled nanopores. J Phys Chem C 2017; 121: 15675-15686.

108. Mark P, Nilsson L. Structure and dynamics of the TIP3P, SPC, and SPC/E water models at 298 K. J Phys Chem A 2001; 105: 9954-9960.

109. Franco LFM, Castier M, Economou IG. Anisotropic parallel self-diffusion coefficients near the calcite surface: a molecular dynamics study. J Chem Phys 2016; 145: 084702.

110. Argyris D, Cole DR, Striolo A. Ion-specific effects under confinement: the role of interfacial water. ACS Nano 2010; 4: 2035-2042.

111. Ho TA, Argyris D, Cole DR, Striolo A. Aqueous $\mathrm{NaCl}$ and $\mathrm{CsCl}$ solutions confined in crystalline slit-shaped silica nanopores of varying degree of protonation. Langmuir 2012; 28: 1256-1266.

112. Ho TA, Argyris D, Papavassiliou DV, Striolo A, Lee LL, Cole DR. Interfacial water on crystalline silica: a comparative molecular dynamics simulation study. Mol Simulat 2011; 37: 172-195.

113. Argyris D, Cole DR, Striolo A. Dynamic behavior of interfacial water at the silica surface. J Phys Chem C 2009; 113: 19591-19600.

114. Rotenberg B, Marry V, Dufreche JF, Malikova N, Giffaut E, Turq P. Modelling water and ion diffusion in clays: a multiscale approach. CR Chim. 2007; 10: 1108-1116.

115. Loganathan N, Kalinichev AG. Quantifying the mechanisms of site-specific ion exchange at an inhomogeneously charged surface: case of $\mathrm{Cs}^{+} / \mathrm{K}^{+}$on hydrated muscovite mica. J Phys Chem C 2017; 121: 7829-7836. 
116. Levesque M, Marry V, Rotenberg B, Jeanmairet G, Vuilleumier R, Borgis D. Solvation of complex surfaces via molecular density functional theory. J Chem Phys 2012; 137: 224107.

117. Tesson S, Louisfrema W, Salanne M, Boutin A, Rotenberg B, Marry V. Classical polarizable force field to study dry charged clays and zeolites. J Phys Chem C 2017; 121: 9833-9846.

118. Pouvreau M, Greathouse JA, Cygan RT, Kalinichev AG. Structure of hydrated gibbsite and brucite edge surfaces: DFT results and further development of the ClayFF classical force field with metal-O-H angle bending terms. J Phys Chem C 2017; 121: 14757-14771.

119. Botan A, Marry V, Rotenberg B, Turq P, Noetinger B. How electrostatics influences hydrodynamic boundary conditions: poiseuille and electro-osmostic flows in clay nanopores. J Phys Chem C 2013; 117: 978-985.

120. Carof A, Marry V, Salanne M, Hansen JP, Turq P, Rotenberg B. Coarse graining the dynamics of nano-confined solutes: the case of ions in clays. Mol Simulat 2014; 40: 237-244.

121. Jeanmairet G, Marry V, Levesque M, Rotenberg B, Borgis D. Hydration of clays at the molecular scale: the promising perspective of classical density functional theory. Mol Phys 2014; 112: 1320-1329.

122. Rotenberg B, Marry V, Salanne M, Jardat M, Turq P. Multiscale modelling of transport in clays from the molecular to the sample scale. CR Geosci 2014; 346: 298-306.

123. Ho LN, Clauzier S, Schuurman Y, Farrusseng D, Coasne B. Gas uptake in solvents confined in mesopores: adsorption versus enhanced solubility. J Phys Chem Lett 2013; 4: 2274-2278.

124. Hu YF, Huang LL, Zhao SL, Liu HL, Gubbins KE. Effect of confinement in nanoporous materials on the solubility of a supercritical gas. Mol Phys 2016; 114: 3294-3306.

125. Luzar A, Bratko D. Gas solubility in hydrophobic confinement. J Phys Chem B 2005; 109: 22545-22552.

126. Pera-Titus M, El-Chahal R, Rakotovao V, Daniel C, Miachon S, Dalmon J. Direct volumetric measurement of gas oversolubility in nanoliquids: beyond Henry's Law. Chemphyschem 2009; 10: 2082-2089.

127. Rakotovao V, Ammar R, Miachon S, Pera-Titus M. Influence of the mesoconfining solid on gas oversolubility in nanoliquids. Chem Phys Lett 2010; 485: 299-303.

128. Gadikota G, Dazas B, Rother G, Cheshire MC, Bourg IC. Hydrophobic solvation of gases $\left(\mathrm{CO}_{2}, \mathrm{CH}_{4}, \mathrm{H}_{2}\right.$, noble gases) in clay interlayer nanopores. $J$ Phys Chem $C$ 2017; 121: 26539-26550.

129. Phan A, Cole DR, Striolo A. Aqueous methane in slit-shaped silica nanopores: high solubility and traces of hydrates. J Phys Chem C 2014; 118: 4860-4868.

130. Phan A, Cole DR, Striolo A. Factors governing the behaviour of aqueous methane in narrow pores. Philos Trans A Math Phys Eng Sci 2015; 374: 20150019.

131. Sakamaki R, Sum AK, Narumi T, Ohmura R, Yasuoka K. Thermodynamic properties of methane/water interface predicted by molecular dynamics simulations. J Chem Phys 2011; 134: 144702.

132. Badmos SB, Striolo A, Cole DR. Aqueous hydrogen sulfide in slit-shaped silica nanopores: confinement effects on solubility, structural, and dynamical properties. J Phys Chem C 2018; 122: 14744-14755.

133. Malani A, Ayappa KG, Murad S. Effect of confinement on the hydration and solubility of $\mathrm{NaCl}$ in water. Chem Phys Lett 2006; 431: 88-93. 
134. Bowers GM, Hoyt DW, Burton SD, Ferguson BO, Varga T, Kirkpatrick RJ. In situ ${ }^{13} \mathrm{C}$ and ${ }^{23} \mathrm{Na}$ magic angle spinning NMR investigation of supercritical $\mathrm{CO}_{2}$ incorporation in smectite-natural organic matter composites. J Phys Chem C 2014; 118: 3564-3573.

135. Kirkpatrick RJ, Kalinichev AG, Bowers GM, Yazaydin AO, Krishnan M, Saharay M et al. NMR and computational molecular modeling studies of mineral surfaces and interlayer galleries: a review. Am Mineral 2015; 100: 1341-1354.

136. Schaef HT, Loganathan N, Bowers GM, Kirkpatrick RJ, Yazaydin AO, Burton SD et al. Tipping point for expansion of layered aluminosilicates in weakly polar solvents: supercritical $\mathrm{CO}_{2}$. Appl Matter Interfaces 2017; 9: 36783-36791.

137. Bowers GM, Loring JS, Schaef HT, Walter ED, Burton SD, Hoyt DW et al. Interaction of hydrocarbons with clays under reservoir conditions: in situ infrared and nuclear magnetic resonance spectroscopy and X-ray diffraction for expandable clays with variably wet supercritical methane. ACS Earth Space Chem 2018; 2: 640-652.

138. Ok S, Hoyt DW, Andersen A, Sheets J, Welch SA, Cole DR et al. Surface interactions and confinement of methane: a high pressure magic angle spinning. Langmuir 2017; 33: 1359-1367.

139. Moucka F, Svoboda M, Lisal M. Modelling aqueous solubility of sodium chloride in clays at thermodynamic conditions of hydraulic fracturing by molecular simulations. Phys Chem Chem Phys 2017; 19: 16586-16599.

140. Svoboda M, Lísal M. Concentrated aqueous sodium chloride solution in clays at thermodynamic conditions of hydraulic fracturing: insight from molecular dynamics simulations. J Chem Phys 2018; 148: 222806.

141. Nezbeda I, Moucka F, Smith WR. Recent progress in molecular simulation of aqueous electrolytes: force fields, chemical potentials and solubility. Mol Phys 2016; 114: 1665-1690.

142. Smith WR, Nezbeda I, Kolafa J, Moucka F. Recent progress in the molecular simulation of thermodynamic properties of aqueous electrolyte solutions. Fluid Phase Equilib 2018; 466: 19-30.

143. Stephen H, Stephen T, eds. Solubilities of Inorganic and Organic Compounds. New York: Macmillan, 1963.

144. Renou R, Szymczyk A, Maurin G, Malfreyt P, Ghoufi A. Superpermittivity of nanoconfined water. J Chem Phys 2015; 142: 184706.

145. Sverjensky DA, Harrison B, Azzolini D. Water in the deep Earth: the dielectric constant and the solubilities of quartz and corundum to $60 \mathrm{~kb}$ and $1200^{\circ} \mathrm{C}$. Geochim Cosmochim Acta 2014; 129: 125-145.

146. Pan D, Spanu L, Harrison B, Sverjensky DA, Galli G. Dielectric properties of water under extreme conditions and transport of carbonates in the deep Earth. Proc Natl Acad Sci USA 2013; 110: 6646-6650.

147. Bonthuis DJ, Gekle S, Netz RR. Dielectric profile of interfacial water and its effect on double-layer capacitance. Phys Rev Lett 2011; 107: 166102.

148. Bonthuis DJ, Netz RR. Unraveling the combined effects of dielectric and viscosity profiles on surface capacitance, electro-osmotic mobility, and electric surface conductivity. Langmuir 2012; 28: 16049-16059.

149. Schaaf C, Gekle S. Spatially resolved dielectric constant of confined water and its connection to the non-local nature of bulk water. J Chem Phys 2016; 145: 084901.

150. Ghoufi A, Szymczyk A, Renou R, Ding M. Calculation of local dielectric permittivity of confined liquids from spatial dipolar correlations. EPL J 2012; 99: 37008. 
151. Zhu PP, Stebner AP, Brinson LC. A numerical study of the coupling of elastic and transformation fields in pore arrays in shape memory alloy plates to advance porous structure design and optimization. Smart Mater Struct 2013; 22: 094009.

152. Fumagalli L, Esfandiar A, Fabregas R, Hu S, Ares P, Janardanan A et al. Anomalously low dielectric constant of confined water. Science 2018; 360: 1339-1342.

153. Zhu H, Ghoufi A, Szymczyk A, Balannec B, Morineau D. Anomalous dielectric behavior of nanoconfined electrolytic solutions. Phys Rev Lett 2012; 109: 107801.

154. Renou R, Ghoufi A, Szymczyk A, Zhu H, Neyt JC, Malfreyt P. Nanoconfined electrolyte solutions in porous hydrophilic silica membranes. J Phys Chem C 2013; 117: 11017-11027.

155. Shock EL. Chemical environments of submarine hydrothermal systems. Origins Life Evol B 1992; 22: 67-107.

156. Foley SF, Prelevic D, Rehfeldt T, Jacob DE. Minor and trace elements in olivines as probes into early igneous and mantle melting processes. Earth Planet Sci Lett 2013; 363: $181-191$.

157. Le T, Striolo A, Turner CH, Cole DR. Confinement effects on carbon dioxide methanation: a novel mechanism for abiotic methane formation. Sci Rep 2017; 7: 9021.

158. Holm NG, ed. Marine Hydrothermal Systems and the Origin of Life - Report of SCOR Working Group 91. Dordrecht: Kluwer, 1992.

159. Brack A, ed. The Molecular Origins of Life: Assembling Pieces of the Puzzle. Cambridge: Cambridge University Press, 1998. 